\title{
Helping in the Workplace: A Social Cognitive Perspective
}

\author{
Julie Lynn Kalanick
}

Dissertation submitted to the faculty of the Virginia Polytechnic Institute and State University in partial fulfillment of the requirements for the degree of

\author{
DOCTOR OF PHILOSOPHY \\ in \\ Psychology
}

\author{
APPROVED: \\ Neil Hauenstein, Ph.D., Committee Chair \\ Roseanne Foti, Ph.D. \\ Danny Axsom, Ph.D. \\ Kevin Carlson, Ph.D.
}

April 4, 2008

Blacksburg, VA

Keywords: Organizational Citizenship Behaviors, OCBs, CAPs, Person by Situation Interactions, Self-Regulation, Social Cognitive Theory, Control Theory, Meta-Theory 


\title{
Helping in the Workplace: A Social Cognitive Perspective
}

\author{
Julie Lynn Kalanick \\ Neil Hauenstein, Ph.D., Committee Chair \\ Psychology
}

\section{(ABSTRACT)}

This study employed an experimental design intended to be an analog to the workplace to examine a person by situation interactive effect on OCBs, which were evaluated as prosocial behaviors. This study also sought to provide initial empirical support for the two-stage social cognitive model of OCBs proposed by Hauenstein and Kalanick (2008). Participants were 194 undergraduates. The study was a 2 (Helpfulness) by 2 (Fairness) design. After completing distracter tasks 1 and 2, participants received either a helpfulness prime or a control prime (task 3). Participants then either experienced either a fair manipulation or an unfair manipulation. Results indicated a distinction between the decision to help and helping effort, which has not been thoroughly examined in literature on OCBs. Results revealed main effects for the helpfulness prime and fairness manipulation on the decision to engage in helping. The nature of these effects was that participants helped more when they were primed with helpfulness and when they experienced fairness. However, once helping commenced, there was an interactive effect between helpfulness and fairness such that the helpfulness prime had a stronger effect on participants treated unfairly. Implications for future research on OCBs are discussed. 


\section{ACKNOWLEDGEMENTS}

My most heartfelt gratitude goes to my parents, Mickey and Kathy, for their never ending love, kindness, encouragement, and support during my life. They truly are the wind beneath my wings and I am who I am today because of their solidarity and sacrifice. I am so blessed to have them as my parents and I hope to provide as much for my future children as they have always given to me.

Similarly, I thank my soon-to-be husband Mark for always standing by my side and comforting me during my many 'bouts of anxiety.' Mark's faith in my abilities and unwavering support gave me the confidence I needed to persevere through numerous hard times. He is a wonderful coach and an even better friend, and I am blessed to have his love.

I am sincerely grateful to Dr. Neil Hauenstein, my advisor and friend, for his unvarying encouragement, patience, and mentorship during the past four years. I greatly appreciate all of the effort he expended on stretching my thinking, instilling confidence, and calming my anxieties. Neil is an amazing instructor in every way and as I embark on my career as an I/O Psychologist, I hope to make him proud.

I also extend my appreciation to Dr. Roseanne Foti, Dr. Danny Axsom, and Dr. Kevin Carlson for their expert guidance, not just on my Dissertation, but throughout my graduate training. Their passion for comprehension and critical thinking has shaped my analytical skills, which will solidly equip me for future challenges.

Finally, I would like to thank Ben Zora, Courtney Kimball, Casey Owens, Sean McColl, Sydney Henderson, and Lida Merritt for all of their assistance as Research Assistants. I am grateful for all of their hard work and meticulousness. 


\section{TABLE OF CONTENTS}

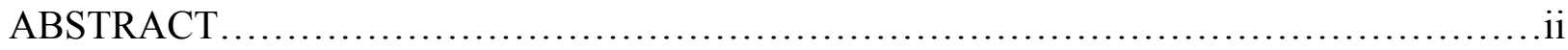

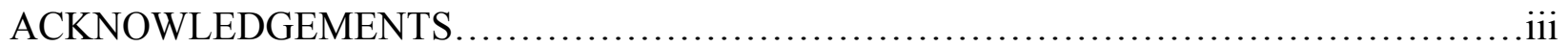

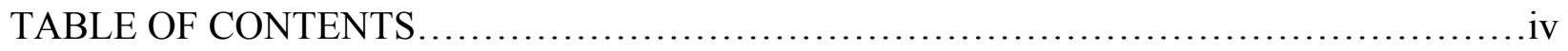

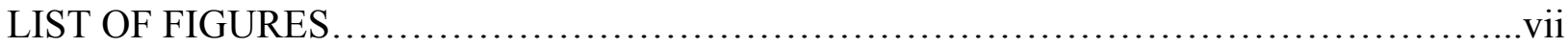

LIST OF TABLES.................................................................

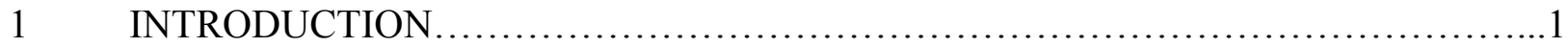

1.1 The Person-Situation Taxonomy and Current OCB Models...................2

1.1.1 Person Models.....................................................

1.1.2 Situation Models...................................................4

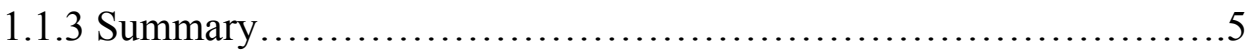

1.2 Person by Situation Models.................................................

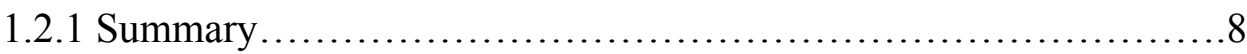

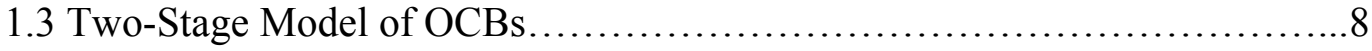

1.3.1 Stage 1: Decision to Engage in an OCB.........................

1.3.1.1 Goal-related CAUs....................................10

1.3.1.2 Helping Cues...........................................11

1.3.2 Helping Cues and Cognitive Affective Processing...................11

1.3.2.1 Situational Assessments.................................11

1.3.2.2 Self-Perceptions...................................11

1.3.3 Stage 2: Regulating OCBs................................... 12

1.3.4 Summary of Two Stage Model of OCBs...........................13

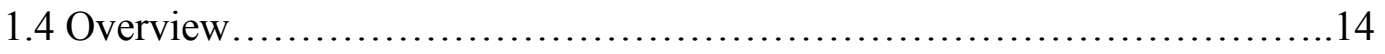


1.4.1 Priming Knowledge Structures.................................15

1.4.2 Design of the Present Study.....................................16

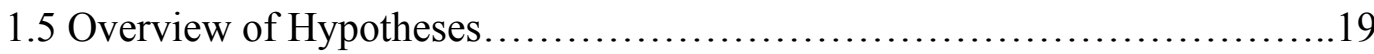

1.5.1 Stage 1 Predictions............................................ 19

1.5.2 Stage 2 Predictions............................................20

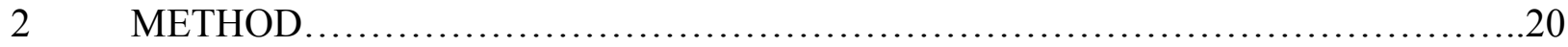

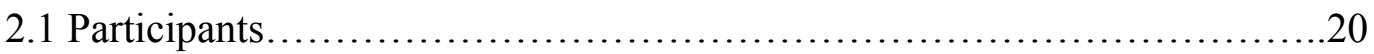

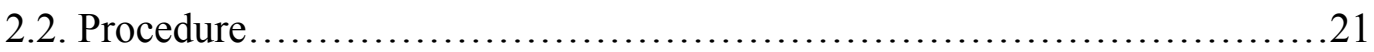

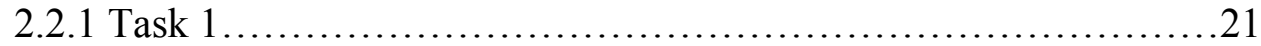

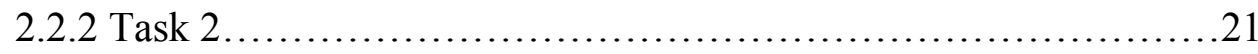

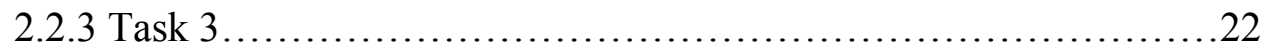

2.3. Individual Difference Measures.......................................22

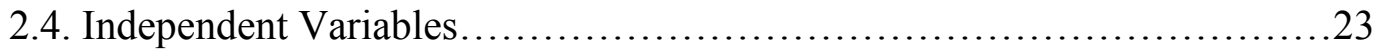

2.4.1 Helpfulness..................................................23

2.4.2 Equity Manipulation..........................................24

2.5 Dependent Variables................................................... 25

2.5.1 Helping Rate...............................................25

2.5.2 Helping Effort..............................................25

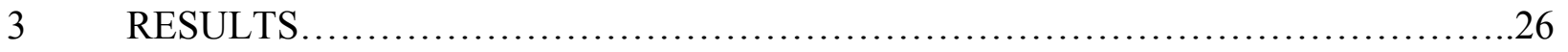

3.1 Descriptive Statistics for Stage 1: The Decision to Help...................26

3.2 Stage 1 Hypotheses................................................26

3.3 Descriptive Statistics for Stage 2: The Self-Regulation of OCBs.............27

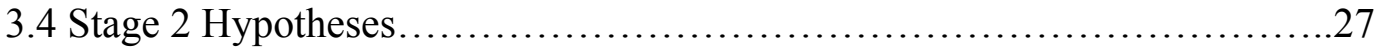




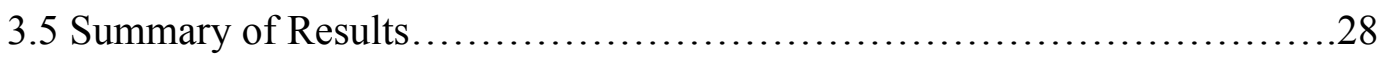

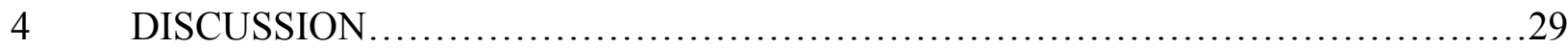

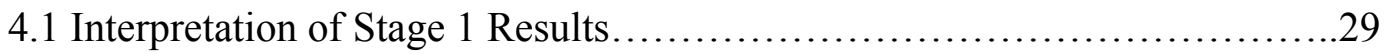

4.1.1 Helpfulness..................................................30

4.1 .2 Equity...................................................... 30

4.1.3 Helpfulness and Fairness Interaction............................31

4.2 Interpretation of Stage 2 Results.......................................

4.2.1 Helpfulness and Equity.......................................... 32

4.3 Summary and Implications for Research...............................32

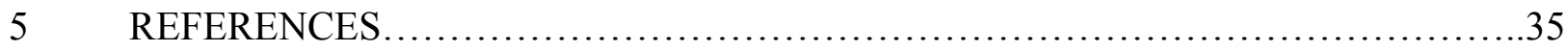

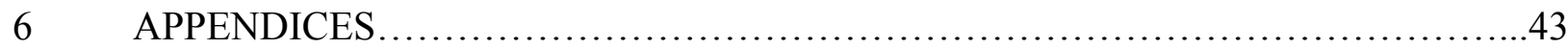

6.1 Appendix A: Informed Consent Form.................................44

6.2 Appendix B: The PANAS ............................................46

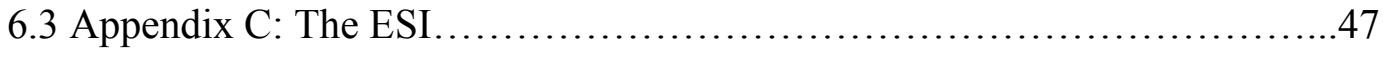

6.4 Appendix D: The IPIP.............................................. 48

6.5 Appendix E: Vignettes and Instructions for their Administration.............50

6.6 Appendix F: Helpfulness Prime.......................................51

6.7 Appendix G: Control Prime........................................52

6.8 Appendix H: Fairness Signature Form................................53

6.9 Appendix I: Unfairness Signature Form...............................54

6.10 Appendix J: Debriefing Form for Participants in Fair Condition.............55

6.11 Appendix K: Debriefing Form for Participants in Unfair Condition..........56

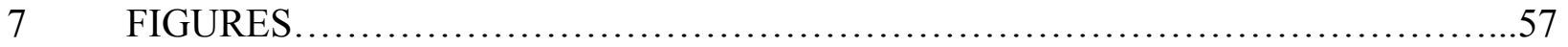




\section{LIST OF FIGURES}

Figure 1: Stage 1: The Decision to Engage in an OCB............................58

Figure 2: Stage 2: Self-Regulation of Superordinate OCB Goals ....................59

Figure 3: Helping Rate for the 2 (Helpfulness) x 2 (Fairness) design .................60

Figure 4: Mean Helping Effort for the 2 (Helpfulness) x 2 (Fairness) design ............61

\section{LIST OF TABLES}

Table 1: Summary of Proposed or Investigated Antecedents of Organizational Citizenship Behaviors.

Table 2: Percentage of Helpers in each Condition of the 2(Helpfulness) x 2(Fairness) design .64

Table 3: Logistic Regression for Prediction of Decision to Help from Helpfulness and

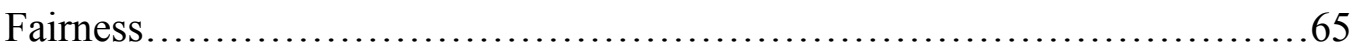

Table 4: Descriptive Statistics for Helpers with Helping Effort.....................66

Table 5: Summary of MRA for Helpers for predicting Helping Effort from the 2 (Helpfulness) x 2 (Fairness) design...................................67 


\section{INTRODUCTION}

Throughout a given work week, there are many instances of helping behaviors performed by employees that contribute to organizational efficiency and effectiveness in a manner independent of task performance (Katz \& Kahn, 1966; Organ, 1997). These organizational citizenship behaviors (OCBs) are prosocial gestures performed with the intent of helping or benefiting another employee or the organization and are "vital for organizational survival, yet difficult or impossible to prescribe as part of an individual's formal job and role requirements" (Brief \& Motowidlo, 1986, p. 710). Recently OCBs have been characterized as a domain of contextual performance in that both constructs are defined as "support[ing] the organizational, social, and psychological environment in which the technical core must function" (Borman \& Motowidlo, 1993, p. 73; Borman \& Motowidlo, 1997; Organ, 1997). As such, OCBs enable a more stable workforce and increased fluidity in organizational functioning and utilization of resources (Bateman \& Organ, 1983; Borman \& Motowidlo, 1997; Katz \& Kahn, 1966; Netemeyer, Boles, McKee \& McMurrian, 1997; Smith, Organ \& Near, 1983). Thus, OCBs play an integral role in optimal organizational functioning.

Over the past two decades, a myriad of antecedents have been proposed in connection with OCBs (e.g., for reviews see Hoffman, Blair, Meriac, \& Woehr, 2007; Organ \& Ryan, 1995; Podsakoff, Mackenzie, Paine, \& Bacharach, 2000) (see Table 1). These antecedents have been commonly catalogued within a meta-framework as either person or situation explanations. This classification scheme has resulted in research focused on exploring main effect relationships with the goal of demonstrating that one category of antecedents is more explanatory than the other (e.g., Moorman, 1993; Organ \& Konovsky, 1989; Williams \& Anderson, 1991). 
However, the underlying premise of such research is that there is interplay between combinations of person and situation variables. As such, I argue that attempting to understand OCBs as caused solely by main effects is lacking; research needs to examine interactive personsituation effects (e.g., Joireman, Kamdar, Daniels, \& Duell, 2006; Kamdar, McAllister, \& Turban, 2006; Podsakoff et al., 2000). The current study adopts such an interactive approach towards OCBs within a social cognitive framework. Using this framework, my study was designed to test the fundamental premise that interactions between person and situation variables are necessary to fully understand OCBs.

\subsection{The Person-Situation Taxonomy and Current OCB Models}

\subsubsection{Person Models}

Attitudinal explanations of OCBs have received a great deal of attention in research on OCBs (Hoffman et al., 2007; Organ \& Ryan, 1995; Podsakoff et al., 2000). The most frequently examined attitudinal variables are based on conceptualizations of job satisfaction. This includes overall satisfaction (Bateman \& Organ, 1983; Motowidlo, 1984; Organ, 1988; Organ \& Lingl, 1995; Smith et al., 1983; Wagner \& Rush, 2000) and job satisfaction as determined by fairness cognitions and affect about the job (Moorman, 1993; Organ \& Konovsky, 1989; Williams \& Anderson, 1991). Other commonly investigated person variables include organizational/job commitment (Schappe, 1998; Wagner \& Rush, 2000; Williams \& Anderson, 1991), positive and negative state mood (George, 1991; Messer \& White, 2006), affect orientation (Lee \& Allen, 2002; Moorman, 1993; Smith et al., 1983; Williams \& Anderson, 1991), personality traits, especially conscientiousness and agreeableness (King, George, \& Hebl, 2005; Neuman \& Kickul, 1998; Organ \& Lingl, 1995), and trust in a leader/supervisor (Coyle-Shapiro, 2002;

Wagner \& Rush, 2000; Watt \& Shaffer, 2005). More recently, research has focused on prosocial 
personality (Penner, Midili, \& Kegelmeyer, 1997), empathy (Joireman et al., 2006; Kamdar et al., 2006), needs or motives (Finkelstein \& Penner, 2004; Penner et al., 1997; Rioux \& Penner, 2001), and role-related variables such as in-role citizenship orientation (Vey \& Campbell, 2004), OCB role definition/identity (Finkelstein \& Penner, 2004; Kamdar et al., 2006).

The job attitude, affectivity, and trait explanations of OCBs have been included in metaanalyses conducted by Organ and Ryan (1995), Podsakoff et al. (2000), and Hoffman et al. (2007). Regardless of the operationalization of the OCB criterion, (e.g., as a composite measure, versus a two-dimensional measure, versus a five-dimensional measure), the various job attitudes have been the most consistently supported person-explanations of OCBs and they tend to explain comparable amounts of variance. However, the effects for person variables are modest at best (Hoffman et al., 2007).

The reality is that these person explanations are best at describing relationships with OCBs aggregated across situations and time. That is, individuals who tend to possess a certain person characteristic (e.g., job satisfaction or positive affectivity) are more likely to engage in OCBs than persons who do not possess certain person characteristics. Although useful, such descriptions do not explain engaging in-and sustaining efforts towards-OCBs in a given context. Examples of basic questions that person models cannot adequately address with any clarity include: How likely is it that a person variable operates as a main effect given the helping context likely elicits perceptions of the situation? Does a person variable affect the decision to engage in the helping behavior in the same manner as it affects the decision to stop or continue helping (i.e., self-regulation of helping effort)? 


\subsubsection{Situation Models}

Historically, equity/fairness perceptions have been the most commonly investigated situational explanation of OCBs (Konovsky \& Organ, 1996; Messer \& White, 2006; Watt \& Shaffer, 2005). Other situational explanations include workplace norms (Ehrhart \& Naumann, 2004), exchange relationships (Blau, 1964; Cardona, Lawrence, \& Bentler, 2004; Farh,

Podsakoff, \& Organ, 1990; Leventhal, 1976; Newman \& Kickul, 1998; Smith et al., 1983; Organ \& Konovsky, 1989), supervisor/leader behaviors (Dineen, Lewicki, \& Tomlinson, 2006; Farh, Podsakoff, \& Organ, 1990; Podsakoff et al., 2000; Schnake, Cochran, \& Dumler, 1995; Smith et al., 1983), task characteristics (Farh et al., 1990; Podsakoff et al., 2000), organization/work-unit behavior (Olkkonen \& Lipponen, 2006), and intrinsic/extrinsic motivation (Deci, 1972; Deci, Benware, \& Landy, 1974; Gagne \& Deci, 2005). Additionally, explanations of OCBs have been proposed whereby the effects of situation variables on OCBs are mediated by person variables. Suggested person variable mediators include trust in supervisor (Konovsky \& Pugh, 1994; Watt \& Shaffer, 2005), and psychological empowerment (Watt \& Shaffer, 2005).

Meta-analyses have found comparable effects for fairness perceptions and job-attitudes in the explanation of OCBs (Hoffman et al., 2007; Organ \& Ryan, 1995; Podsakoff et al., 2000). Additionally, the meta-analysis by Podsakoff et al. (2000) found reliable effects between task characteristics and OCBs and between various forms of leader behaviors (including leader member exchange, supportive leader behaviors, and transformational leadership) and OCBs.

Although the conditional nature of situational explanations makes them better suited than person explanations to explain OCBs in a given helping context, person variables likely simultaneously contribute. Furthermore, as with the person explanations, the situational 
explanations do not separate the issue of the decision of engaging in an OCB from the regulation of OCB behavior.

\subsubsection{Summary}

Although parsimonious, the simplicity of the person versus situation classification scheme is also its critical limitation. For one, the classification of OCB-explanations into either a person or a situation category is not always clearly justified as the boundary separating the person from the environment cannot be clearly delineated (Higgins, 1999). Second, even if correctly accomplished, the person-situation classification adds little to the understanding of the OCB process. Instead, this taxonomy has led to research focused on mundane comparisons of whether main-effect person or situation explanations account for more variance in OCBs. Further, the nature of this "either/or" taxonomy has downplayed the criticality of examining interactive effects on OCBs.

\subsection{Person by Situation Models}

In addition to the aforementioned main-effect explanations of OCBs, a few interactive models of OCBs have been empirically tested. Messer \& White (2006) conducted an experimental field study to examine the interaction between fairness perceptions and mood state on reporting of OCBs. Employees were randomly assigned to one of four conditions in a 2 (positive mood vs. neutral mood) x 2 (fair vs. unfair work-scenario) design. All procedures were administered via a packet of written materials given to each employee. Employees first filled out baseline measures of mood and engagement in OCBs. Employees then received either the mood induction or completed the fair/unfair work-scenario task, counterbalanced within condition. Positive mood was induced through asking employees to concentrate on a series of mood statements, while in the neutral mood condition, participants were asked to focus on neutral 
statements. For the fair/unfair scenario task, employees were asked to imagine that a written work scenario (either fair or unfair) was happening to them. Employees then filled out the same OCB measure as before, but were asked to fill it out as if they had experienced either the fair/unfair situation. Results indicated a main effect for fairness on the likelihood of performing OCBs, with those treated unfairly being less likely to perform OCBs than those treated fairly. Although support was not found for the hypothesized interaction, the researchers cited that problems with the mood induction procedure prevent concrete conclusions from being drawn.

Kamdar et al. (2006) examined interactions between situational procedural justice and individual differences in reciprocation wariness (RW), perspective taking (PT), and empathetic concern (EC), in relation to OCB role definition, and also examined the interaction between procedural justice and OCB role definition, in relation to OCBs. Employees provided information on procedural justice, the aforementioned individual difference variables, and roledefined loyal boosterism and role-defined interpersonal helping, and supervisors provided information on employees' performance of loyal boosterism- and interpersonal helping-OCBs. Of primary interest is the analysis examining the interaction between procedural justice and role definition on both forms of OCBs. Specifically, after controlling for procedural justice and the individual difference variables of RW, PT, and EC, and $\mathrm{OCB}$ role definition, the interaction between procedural justice and OCB role definition was significant for both supervisor-rated loyal boosterism and interpersonal helping. The nature of this interaction was that for both types of OCBs, procedural justice was related to OCB only when OCB role definition was low.

Jorieman et al. (2006) examined the interaction between employees' situational time horizon with the organization and both their dispositional empathy and dispositional concern for future consequences, in regards to their willingness to engage in OCBs. Of relevance to the 
current paper are the procedure/results of studies 2 and 3. In study 2, employees filled out measures of their empathy and concern for future consequences during phase 1. During phase 2 (two and a half weeks later), employees were randomly assigned to have made salient either a short-term anticipated time horizon or a long-term anticipated time horizon. Following this procedure, they filled out a measure on their likelihood of engaging in OCBs. Study three only had one phase where employees filled out measures of empathy, concern for future consequences, and anticipated time horizon with their organization. Their supervisors provided ratings of their OCBs. Across the two studies, the interactions between these person and situation variables were consistently supported, in relation to both overall OCBs and dimensions of OCBs. Specifically, there was an interaction between empathy and anticipated time horizon such that having a short-term time horizon led to significantly less OCBs than having a long-term time horizon, among those who were low in empathy but not high in empathy. For those high in empathy, the impact of time horizon was less potent. And, there was an interaction between anticipated time horizon and concern for future consequences on OCBs such that having a shortterm time horizon resulted in less OCBs compared with having a long term horizon, but only for those high on CFC. When CFC was low, there was a very weak relationship between anticipated time horizon and OCBs.

Other models of OCBs emphasize a dynamic interplay between person and situation variables, but do not explicitly propose a statistical interaction between these antecedents. Penner et al. (1997) suggest that dispositional motives, dispositional prosocial personality orientation, job attitudes, mood on the job, organizational variables, and "other kinds of personal, demographic, and situational variables not specified in the model" collectively result in intermediate $\mathrm{OCB}$, which, over time, results in citizen role identity and eventually leads to 
enduring OCBs (p. 128). Additionally, Ehrhart \& Naumann (2004) discuss how group-prescribed norms influence individual-level norms to impact individual OCBs.

Overall, the statistical interaction models explain OCBs as simplistic contingencies. For example, individuals in a positive mood are more likely to perceive the situation to be fair, thereby increasing the likelihood of engaging in OCBs. In contrast, the dynamic models focus on the relationships among broad categories of person and situation antecedents, and their relationships with OCBs. However, in dynamic models, the explanation of OCB processes is simply the specification of the relationships among the antecedent variables. For example, in the Ehrhart and Naumann (2004) normative model of OCBs, group-proscribed OCB norms (situational antecedents) lead to the adoption of a personal norm (a person antecedent) which in turn leads to individual OCBs, and this mediated relationship is moderated by an employee's similarity to the work-group.

\subsubsection{Summary}

Recent research has argued for studying OCB processes as a function of person by situation interactions. The current study adds to this trend in that the study is designed to assess if a powerful situation antecedent of OCBs (i.e., equity perceptions) can be ameliorated by a person variable (i.e., priming of a helpful self-schema). However, the study is predicated on more than just demonstrating this interactive effect. Rather, the research was guided by the development of a two-stage social cognitive model of OCBs (Hauenstein \& Kalanick, 2008).

\subsection{Two-Stage Model of OCBs}

The present model of OCBs (i.e., Hauenstein \& Kalanick, 2008) is derived from the frameworks of Mischel \& Shoda's $(1995,1998)$ cognitive-affective processing model (CAPS) and control theory (Carver \& Scheier, 1982). The model is the first to distinguish between the 
decision to engage in an OCB and the self-regulation of OCB effort. Although the same antecedents affect both the decision to help and the self-regulation of effort, they potentially operate differentially in each stage warranting separate conceptualization in the model. Furthermore, certain variables affect the self-regulation of OCBs that do not affect the helping decision, most notably goals formed after the decision to help and memories regarding the decision to render assistance.

\subsubsection{Stage 1: Decision to Engage in an $O C B$}

Each individual has a unique and complex hierarchy of mental representations, or cognitive-affective processing units, (CAUs), that dictate an individual's interpretation of situations. These CAUs are an amalgamation of self-schemas, self-perceptions, self-evaluations, situation perceptions, person perceptions, competencies, valences attributed to outcomes, goals and expectancies, self-regulations, feeling-states, and memories of past experiences (Mischel, 2004; Mischel \& Shoda, 1995, 1998). Individuals differ with respect to the organization, interconnections, and strength of these CAUs, which has implications for their accessibility and availability in a given context. Therefore, understanding the antecedents of helping behavior requires understanding the meaning that the person ascribes to situational characteristics, which is a function of the CAUs activated in response to them. It follows that a person's attitudes and preferences (e.g., job satisfaction, affect, personal norms) do not operate only as main effect causes of OCBs, but are "situationally hedged, conditional, and interactive with the situations in which they were expressed" (p. 5). Conceptualizing OCBs from this framework enables researchers to account for the dynamism in the antecedents that lead to discrete helping acts, and also allows understanding of a person's global helping patterns. 
Figure 1 presents the decision phase of the OCB process. To explain the decision-making process for engaging in OCBs, I first explain the path from the variable willingness to help to goal-related CAUs (Figure 1, Path 5). Willingness to help represents a person's 'readiness' to provide assistance and reflects the individual's overall perception of both his/her ability to render assistance and his/her motivation to render assistance in a specific helping context. Due to its dependence on the properties of the situation, willingness to help is not a dispositional variable, but is generated in response to each helping opportunity, based on perceptions of the situation at hand, the recall of judgments rendered in response to other helping opportunities, or a combination of current perceptions and judgments recalled from memory.

1.3.1.1 Goal-related CAUs. Regardless of whether a person decides to help or not to help, he/she forms implicit or explicit goals for his/her behavior in the current situation (Figure 1, Path 5). These goals function to direct and maintain behavior in pursuit of a desired end state. For example, if the person decides not to help, he/she will form goals relevant to extricating him-/ herself from the situation (e.g., making a 'good excuse' for not helping). And, assuming the person decides to help, he/she will form goals for his/her intended helping behavior. These goals potentially include the amount of time and/or effort that he/she intends to expend on helping as well as the intended endpoint of the helping behavior (e.g., help until the task is completed versus help until the recipient is in more control).

Implicit in the formation of goals is the 'yes/no' helping decision. This implies a selfregulatory process where a person's willingness to help serves as input for a comparator where a referent value (i.e., a threshold) is available. This willingness to help threshold can be a knowledge structure available in long-term memory based on amalgamation of prior helping experiences, or a knowledge structure formed in working memory in response to the current 
helping cues, or a knowledge structure representing the current perception of helping cues to adjust the long-term memory threshold in working memory.

1.3.1.2 Helping cues. Turning to the front half of the decision model, we posit that salient contextual features of the situation are the 'external' elements that initiate the 'internal' OCB decision-process. These external elements or helping cues initiate the cognitive-affective processing of the situation.

\subsubsection{Helping Cues and Cognitive Affective Processing}

Cognitive processing of helping cues in a given situation occurs primarily through two categories of CAUs labeled as situational assessments and self-perceptions. There is likely a dynamic interplay between these categories. As such, the boxes surrounding self-perceptions and situational assessments in Figure 1 (and Figure 2) are represented with permeable boundaries. Theoretically, we view the aforementioned distinction between person and situational variables as an arbitrary distinction in most contexts. However, because a self-perception can affect willingness to help without reference to a situational assessment, and vice versa, it is useful to retain the person—situation distinction, especially for meta-theoretical purposes.

1.3.2.1 Situational assessments. The presence of helping cues leads to a psychological assessment of the helping situation (Figure 1, Path 1) or, the formation of situation-specific perceptions. These situational assessments represent any overarching quality the employee believes characterizes the situation at hand, which directly affects the employee's willingness to help (Figure 1, Path 3). The traditionally catalogued situational explanations of OCBs represent different types of situational assessments.

1.3.2.2 Self-perceptions. The category of self-perceptions refers to cognitions and emotions that form the foundation of an employee's self-perceptions and construal regarding 
his/her relationship with fellow employees, the work unit, and the organization as a whole. Each employee has a unique hierarchy of self-perceptions that has been shaped by his/her unique life experiences. These activated self-perceptions provide a framework that moderates the relationship between helping cues and situational assessments (Figure 1, Path 2) and directly impacts a person's willingness to help (Figure 1, Path 4). However, any number of selfperceptions activated by either the helping cues or due to chronic accessibility, can influence perceptions of situational assessments and willingness to help. Except for dispositional explanations (e.g., personality traits), the traditionally catalogued person explanations of OCBs represent different types of self-perceptions.

\subsubsection{Stage 2: Regulating $O C B S$}

Once an employee decides to render assistance and generates goal-related CAUs, there remains the issue of how much effort he/she will ultimately expend on an OCB and how he/she will navigate the process to stop rendering assistance, or Stage 2 of the model (see Figure 2). The self-regulatory processes are more complex as compared with Stage 1. Specifically, the effort expended on the OCB and the decision of when to cease the OCB depend upon two levels of self-regulatory processes. At a superordinate-level is the self-regulation involved in comparing the individual's current level of willingness to help to his/her current helping threshold in order to make decisions about the continuation of the $\mathrm{OCB}$, labeled as superordinate OCB goals; at a subordinate-level is the self-regulation that reflects the moment-to-moment evaluations of progress towards reducing discrepancies between the current $\mathrm{OCB}$ state and the desired OCB goal end-state.

As with Figure 1, Figure 2 does not graphically depict the underlying self-regulatory processes. Graphic depictions of the regulatory processes being proposed are readily available 
(e.g., Carver \& Scheier, 1982; Carver \& Scheier, 1990). However, Figure 2 does depict the required hierarchically-organized negative feedback loops (Carver \& Scheier, 1982). The superordinate feedback loop (Figure 2, Path 8) is an internal feedback mechanism that inputs the superordinate goals into the self-regulation processing occurring at the subordinate level. The superordinate goals produce strategic decisions regarding the OCB that guides revisions to goalrelated CAUs. The subordinate-level self regulation informs the superordinate OCB goals with current perceptions of goal discrepancies, which produce goal-related CAUs. In turn, the goalrelated CAUs potentially moderate perceptions of situational assessments (Figure 2, Path 3) and/or directly affect willingness to help (Figure 2, Path 5). The external feedback loop (Figure 2, Path 9) reflects the maintenance or adjustments to OCB effort and/or behavior choices as a function of the updated goal-related CAUs. In turn, the produced behaviors become helping cues available for the next cycle of self-regulation.

\subsubsection{Summary of Two Stage Model of OCBs}

In stage 1, each individual's situation-specific willingness to help is the result of cognitive-affective processes initiated by available helping cues. Specifically, helping cues can either activate an individual's self-perceptions and/or perceptions regarding situational assessments, which individually and/or interactively result in the individual's willingness to help (Figure 1, Paths 1-4). An employee's willingness to help ultimately results in goal-related CAUs (Figure 1, Path 5). Specifically, willingness to help serves as input for a helping comparator in which the employee compares his/her willingness to help at that particular moment with a willingness to help threshold, resulting in a decision to help or not to help. The decision to help or not to help results in goal-related CAUs that specify the desired end state for the OCB episode. 
Stage 2 operates in a similar manner to Stage 1 in that perceptions of situational assessments are potentially moderated by person variables (Figure 2, Path 2) thereby impacting willingness to help (Figure 2, Path 6), which in turn determines the superordinate decision to continue the OCB or cease the OCB (Figure 2, Path 7). This decision serves as input to the subordinate level that another cycle of cognitive affective processing is required (Figure 2, Path 8). However, there are several added complexities in Stage 2. At the superordinate decisionlevel, current helping behaviors serve as helping cues (Figure 2, Path 9) and goal-related CAUs also can moderate the perceptions of helping cues (Figure 2, Path 3). At the subordinate level, there are complex self-regulatory processes that manage the discrepancies between desired end states and goal-related CAUs.

\subsection{Overview}

The proposed model by Hauenstein \& Kalanick (2008) is broad in scope and can be empirically tested in many different ways. As a first empirical test of the model, the goal is to examine the overarching proposition that OCBs are a function of perceptions of helping cues as translated through the lens of self-perceptions, and that antecedents may have different effects in Stage 1 and Stage 2. More precisely, I will test if the magnitude of the effect of a situational assessment (equity perceptions) on OCBs can be affected by the activation of a self-perception (helpfulness) via priming, and I will examine these effects in terms of the decision to render aide and in terms of the self-regulation of those who decide to help. I have chosen equity perceptions (Adams, 1965) as a situational assessment because they have routinely been shown to have a strong effect on OCBs (see Table 1). Therefore, if the traditional equity effects can be reduced or eliminated as a function of self-perceptions, then such a finding not only assimilates with the emerging position that OCBs are a function of interactive effects, but also represents strong 
support for Hauenstein \& Kalanick's (2008) social cognitive model of OCBs. More specifically, such findings will indicate that competing explanations of OCBs are better thought of as complimentary explanations and that the current model of OCBs has utility as a meta-theoretical organizing and explanatory framework.

\subsubsection{Priming Knowledge Structures}

Research has demonstrated that knowledge structures are paramount in understanding the link between perception and behavior because upon activation, knowledge structures serve as interpretative frameworks for information processing (Higgins, 1996). Priming operates through temporarily increasing the accessibility of a knowledge structure which increases the probability that the knowledge structure (and not another equally applicable knowledge structure) will be activated in response to a subsequently presented stimulus (Higgins, 1996).

While priming experiments have typically focused on the effects of activating trait constructs or stereotypes on impression formation (e.g., Higgins, Rholes, \& Jones, 1977; Srull \& Wyer, 1979), the effects of priming trait constructs and stereotypes on behavior have been the focus of more recent attention (Dijksterhuis, Aarts, Bargh, \& van Knippenberg, 2000;

Dijksterhuis \& Bargh, 2001; Wheeler \& Petty, 2001). Research supports a robust effect for this phenomenon, explained by overlap between knowledge structures of perceptions of traitconstructs and knowledge structures for corresponding behavioral tendencies (Bargh, Chen \& Burrows, 1996; Dijksterhuis \& Bargh, 2001; Wheeler \& Petty, 2001). For example, priming rudeness led to more interrupting of a conversation than priming kindness (Bargh et al., 1996), and priming helpfulness has led to picking up dropped items (Macrae \& Johnson, 1998). Additionally, priming intelligence has led to enhanced performance on a knowledge test versus priming stupidity (Dijksterhuis \& van Knippenberg, 1998). 
Given the demonstration that priming traits typically leads to concomitant behavior, I decided to prime a Self-Schema self perception. Indeed, of all the self-perceptions that I discussed above (i.e., Self-Schemas, Work Attitudes, Relationships with Others, Current State Perceptions, and Self-Evaluations), the category of Self-Schemas appears most similar to the trait perceptions and stereotypes that have been reliably primed (Dijksterhuis \& Bargh, 2001; Macrae \& Johnston, 1998; Wheeler \& Petty, 2001). More specifically, I have chosen the Self-Schema of 'Helpfulness' because I am confident that most people have a mental-representation of what it means to be helpful and to perform helpful behaviors (Macrae \& Johnston, 1998). Additionally, various aspects of my experimental paradigm pose constraints on my ability to cleanly measure/ prime other self-perceptions (which will be discussed below).

\subsubsection{Design of the Present Study}

The design of the current study is a modified version of Kalanick and Hauenstein (2007a) that includes changes based on research-experience and the inclusion of priming a self perception. Kalanick and Hauenstein (2007a) conducted an experiment to evaluate OCBs as a more general form of helping behaviors, or prosocial behaviors. Participants were recruited under the false premise that the experiment was aimed at understanding how personality relates to judgments about juvenile delinquency. They were told the study would take 2-3 hours over two phases, and was worth three extra credit points. During Phase 1, participants filled out three individual difference measures and two weeks later, they came to the lab for Phase 2. During Phase 2, participants spent one hour writing about case studies of juvenile delinquents and then they experienced an equity manipulation. Participants were randomly assigned to experience either equity, inequity, or a control. The equity manipulation involved the number of extra credit points that they believed they were receiving. Following the manipulation, participants were 
given a 15-minute wait period in which they could watch a video, perform a personal task, or help score Wonderlic measures, the latter representing an OCB.

While interesting results emerged from using the aforementioned protocol, there were a few issues. For one, a low percentage of helpers emerged (33.5\%) which led to a small sample size for statistical analyses $(n=63)$. Participants had too many options available to occupy them during the 15-minute wait period. Specifically, when participants were given the 15 -minute waitperiod, many used personal belongings (like Laptops, IPODs, and Cell-Phones) instead of choosing from amongst the available alternatives (e.g., watching TV, scoring Wonderlics, or just waiting). Second, it appeared that the equity manipulation was confounded with extrinsic motivation. Specifically, in the fair-manipulation, participants were given a 'breakdown' of the amount of extra credit they were receiving and how it was allocated amongst the tasks they completed. Comparison of helping in the fair condition relative to the other conditions led to the belief that making such 'specific rewards' salient reduced intrinsic motivation for participants regarding the experiment.

As a result of the issues in Kalanick and Hauenstein (2007a) and in an effort to replicate some of the more interesting findings, a second study was conducted with a few protocol modifications (i.e., Kalanick \& Hauenstein, 2007b). For one, in an attempt to increase the percentage of helpers, participants were not allowed to bring any personal belongings with them into the experiment-room. Participants were given only two options for the 15-minute waitperiod: help score Wonderlic measures, or do nothing. Second, the possibility of an extrinsic motivation effect was examined by using a 2 (Equity vs. Control) X 2 (Intrinsic Motivation vs. Extrinsic Motivation) design. 
While restricting what participants could bring with them into the experiment room increased the percentage of helpers (75\% versus 33.5\% for Kalanick \& Hauenstein, (2007a)), the end results suggested that many helpers assisted to relieve boredom more so than because of the desire to help. Further, no support was found for an intrinsic-extrinsic motivation effect on performance of helping behaviors. The only noteworthy result from Kalanick \& Hauenstein (2007b), was a main effect for the Fair manipulation: participants in the fair condition scored more measures than participants in the control condition.

My growth in understanding OCBs in conjunction with the above studies has been insightful regarding the design of the Dissertation. For one, my new conceptualization of OCBs as being grounded in social comparison principles warrants testing the influence of a selfperception in conjunction with equity on helping behaviors. The decision to prime a Self-Schema self-perception (i.e., Helpfulness) was a function of practicality and congruence with the Kalanick and Hauenstein (2007a, 2007b) protocol. All other categories of self-perceptions were considered, but it was concluded that a Self-Schema self-perception was the easiest to manipulate without creating demand characteristics. After much consideration of different SelfSchemas, 'Helpfulness' was chosen because a 'Helpful' prime could be readily integrated into the experimental task with a low risk of suspicion. Pilot studies (discussed below) confirmed this decision.

Second, procedural issues with Kalanick and Hauenstein (2007a, 2007b) indicated the necessity of modifications for the Dissertation study. Although it is clear that participants need to be restricted as to what they can bring with them into the experiment room, participants also need to be given some choice of activities during the 15 minute wait period. Third, fairness needs to be manipulated in a way that emphasizes that the effort participants are exerting is fair given 
the amount of extra credit. Additionally, post-experimental comments from participants led to a re-evaluation of the length and intensity of the experimental task. Specifically, in Kalanick and Hauenstein (2007a, 2007b), participants were required to analyze case studies and write detailed responses for one hour. This amount of time was decided upon during pilot testing, where it was evident that an hour of work was necessary to create a reasonable context for the equity manipulation. However, in retrospect, the intense nature of this task may have made some participants feel as if they already 'contributed enough' to the experiment, which would have undermined their desire to help. Therefore, the present study includes a task that is an hour long, but less effort-intensive.

\subsection{Overview of Hypotheses}

The following hypotheses are listed separately as a function of Stage 1 (the decision to help) and Stage 2 (self-regulation of an OCB).

\subsubsection{Stage 1 Predictions}

Hypothesis 1: Equity perceptions will affect decisions to render assistance such that "unfairly" treated participants will decline to provide assistance at a greater rate than "fairly" treated participants

Hypothesis 2: Activation of a "helpful" schema will affect decisions to render assistance such that participants primed with helpfulness will help at a higher rate than participants primed with a control.

Hypothesis 3: Activation of a "helpful" schema will modulate the equity effect in that the difference in the percentage of helpers between the equitable and inequitable conditions will be less when helpfulness is primed. 


\subsubsection{Stage 2 Predictions}

Hypothesis 4: There will be a main effect for equity perceptions such that helping participants who are treated "fairly" will expend greater helping effort (continuance) than helping participants who are treated "unfairly."

Hypothesis 5: For helping participants, there will be a main effect of priming the helpfulness schema such that those primed to be helpful will help exert more effort (continuance) than participants not primed with the helpful schema.

Hypothesis 6: Activating the Helpfulness schema will moderate the effects of equity perceptions for helping participants. Specifically, the helpfulness prime effect will be stronger when participants are treated unfairly than when participants are treated fairly.

\section{METHOD}

\subsection{Participants}

A total of 194 undergraduate students from Virginia Tech were recruited to participate in this study. Only students age 18 or older were recruited. The students participated in order to earn two points of extra credit for a psychology class that they were enrolled in that made use of extra credit provided through the Sona System (the Psychology Department's online Experiment Management System). The research project consumed approximately 1.5-2 hrs of their time.

The participants were blind to the true nature of the study. Instead they were informed that the research study was aimed at evaluating how personality relates to judgments about the causes of juvenile delinquency.

The study was publicly advertised to students and the participants were able to register for a time slot using the Psychology Department's online Experiment Management System (Sona 
System). In the advertisements, participants were informed that the experiment would take place in one meeting and would consume approximately 1.5-2 hours of their time.

\subsection{Procedure}

Upon arriving at the lab, each participant was greeted by an experimenter who was blind to the hypotheses of the study, but not blind to the independent and dependent variables. It is important to note that these experimenters underwent a rigorous training regime in which they became experts at delivering scripts to the participants to safeguard against their inadvertently cueing participants with words, expressions, or gestures.

The experimenter brought the participants (maximum three at a time) into one room and conducted the informed consent process. A copy of the Informed Consent form is included as Appendix A. The experimenter locked-up participants' personal belongings. Following the collection of consent forms, each participant was brought to a separate research room. There, they were told that there were three tasks that they had to complete.

\subsubsection{Task 1}

For Task 1, participants were given individual difference measures to fill out. The primary purpose of these measures was to ensure that subjects spend more than an hour working in the laboratory, which is a necessary condition for the equity manipulation. The secondary purpose is to collect measures that provide for exploratory analyses not formally part of the Dissertation (see Appendices B, C, and D for the measures).

\subsubsection{Task 2}

In the second task, subjects were asked to read through case studies of three juvenile delinquents and to respond to each case study in regards to: (a) what aspects of childhood or environment may have contributed to the delinquent's behavior; and (b) how each delinquent's 
current behavior will likely influence their behavior in adulthood (see Appendix E). Participants were told that they had to write at least one page for each case study. They were given 30 minutes to work on Task 2. This helped guarantee that all participants put in the same amount of work (in regards to length and time).

\subsubsection{Task 3}

Following their completion of Task 2, each participant was given Task 3 . The helpfulness manipulation was embedded in the third task. Participants were told that they had 10 minutes to work on Task 3 and that the researcher would return at that time to collect their responses (see Appendices F and G for the Helpful prime and Control prime, respectfully).

Following the 10 minutes, each participant experienced an equity manipulation and signed a form. Specifically, participants experiencing the fair manipulation signed one form (see Appendix H) and participants experiencing the unfair manipulation signed another form (see Appendix I). Then each participant was given a 15-minute opportunity to perform an OCB (i.e., score Wonderlics), read comics (i.e., Dilbert \& Farside) or complete puzzles (i.e., crossword \& word-search). The experimenter then ended the experimental session and debriefed the participants. The debriefing form and procedure differed depending upon which condition each group of participants was in. Specifically, participants experiencing the fair manipulation received one form/procedure (see Appendix J) and the participants experiencing the unfair manipulation received another form/procedure (See Appendix K).

\subsection{Individual Difference Measures}

Participant's trait affectivity was operationalzed through participants' score on the Positive and Negative Affect Scale, or PANAS (Watson, Clark, \& Tellegen, 1988). The PANAS has two scales, one measuring Positive Affectivity (PA) and the other measuring Negative 
Affectivity (NA). Cronbach's coefficient alpha for the PA scale is typically in the upper .80's, and in the mid-80's for the NA scale. See Appendix B for the PANAS.

Equity Sensitivity was operationalzed through respondents' score on the Equity Sensitivity Instrument, or ESI (King \& Miles, 1994). Respondents are asked to allocate points between 5 "Entitled" and 5 "benevolent" statements. See Appendix C for the ESI.

Personality was operationalzed through respondents' scores on a 50-item test derived from the International Personality Item Pool (IPIP). This test assessed each of the five dimensions of the big five personality factors, namely, openness to new experiences, conscientiousness, extraversion, agreeableness and neuroticism (Goldberg, 1999). See Appendix D for the IPIP.

\subsection{Independent Variables}

\subsubsection{Helpfulness}

There were two levels to the self-perception prime. Specifically, participants in the 'Helpfulness' condition were given a task that asked them to write about trait-Helpfulness (see Appendix F). Participants in the control condition were asked to write about what constitutes a juvenile delinquent (see Appendix G).

A pilot study was conducted to validate the main effects of the primes. A total of 28 undergraduate students were recruited from psychology classes at a large south eastern university. The participants participated in order to accrue two extra credit points for their psychology class. The participants were recruited with the cover story discussed above.

The participants first filled out their informed consent form and then completed the casestudy task. Then participants experienced either the Helpfulness $(n=16)$ or Control Prime $(n=$ 12). Immediately after, participants were given the opportunity to perform an $\mathrm{OCB}$, complete 
puzzles, or read comics. Participants were then debriefed and probed for suspicion. The importance of not disclosing the details of the experiment to anyone was stressed to the participants.

The helping prime went through several iterations during pilot testing. In the end, a helpfulness prime was developed that blended with the experimental context and produced the desired effect in regards to behavior intentions of helping. Specifically, after reading a brief cover-story regarding educating juvenile delinquents on the value of helping others, participants are given 10 minutes to list synonyms of helpfulness and to describe their perception of what constitutes a helpful person, including behaviors, values, and lifestyle. This type of prime has been supported by previous research (Bargh et al., 1996; Dijksterhuis \& Bargh, 2001; Dijksterhuis \& van Knippenberg, 1998; Dijksterhuis et al., 2000; Dijksterhuis et al., 2001). In the control condition, participants describe their perception of a juvenile delinquent, including behaviors, values, and lifestyle.

\subsubsection{Equity Manipulation}

There were two levels to the equity manipulation: a fair condition and an unfair condition. In the fair condition, following the participants' completion of Task 3 , the experimenter stated to each participant, "The American Psychological Association (APA) has been monitoring the treatment of participants in experiments, and is asking researchers to provide documentation of the treatment of subjects prior to publishing the research. To this end, we would like you to sign a statement that the effort expended in this experiment was fair given the amount of extra credit." The participant was then given a paper to sign (see Appendix H). In the unfair condition, following the participants' completion of Task 3, the experimenter stated to each participant, "Thank you for your participation in this experiment. The psychology 
department has been auditing the amount of extra credit given in experiments and because you have been here for less than 2 hours, the department has asked us to give only one extra credit point for this study instead of the intended 2 extra credit points. Therefore, you will receive a total of one credit point." The participant was then given a paper to sign acknowledging that he/she was aware of the change (see Appendix I).

\subsection{Dependent Variables}

\subsubsection{Helping Rate}

After the participants finished the tasks and were exposed to the prime and equity manipulation, the experimenter said, "The experiment is over but I need about 15 minutes to compare your responses to Tasks 1-3." The experimenter then motioned to a table in each participant's room that had a stack of the first page of completed Wonderlic measures, puzzles (crossword \& word search), and comics (Dilbert \& Farside). The experimenter then said, "While you wait, feel free to do some puzzles, read some comics, or score some test data to help the Psychology Department with another research study. This is how you score them." The experimenter then instructed the participant on how to score the first page of the Wonderlic, and then left the room for 15 minutes. Helping rate was determined by the percentage of participants in each condition that scored at least one Wonderlic.

\subsubsection{Helping Effort}

For participants who choose to score measures, Helping Effort was determined by the number of Wonderlic tests the participant scored to completion. It takes between 30 seconds and 1 minute to score the first page of the Wonderlic, so the expected range of scores was from zero to approximately 30 . 


\section{RESULTS}

\subsection{Descriptive Statistics for Stage 1: The Decision to Help}

A total of 113 of the 194 participants chose to help (58.2\%) or score at least one Wonderlic measure. Descriptive statistics for the frequency of helping within each condition of the 2 (Helpfulness) X 2 (Fairness) design are presented in Table 2.

\subsection{Stage 1 Hypotheses}

Hypothesis 1 predicted that unfairly treated participants would decline to provide assistance at a greater rate than fairly treated participants. The one-tailed $z$-test for comparing these proportions was significant $(\mathrm{z}=-3.81, \mathrm{p}<.05)$ indicating that unfairly treated participants helped at a lesser rate (44.9\%) than fairly treated participants (71.9\%). Hypothesis 2 predicted that participants primed with helpfulness would help at a higher rate than participants primed with a control. The one-tailed $z$-test for comparing these proportions was also significant $(\mathrm{z}=$ $3.88, \mathrm{p}<.05)$ such that participants primed with helpfulness helped at a higher rate $(71.7 \%)$ than participants experiencing a control prime (44.2\%).

Hypothesis 3 predicted an interaction between the fairness of the condition and the prime of the condition such that the difference in the rate of helping between participants treated fairly and those treated unfairly would be smaller when participants received a helpfulness prime than when they received a control prime. A binary logistic regression was conducted to determine differences in 'yes/no' helping decision in which helpfulness and fairness were entered as main effects in step 1 and step 2, respectively, and their interaction was entered in step 3 (see Table 3). The change in chi-square and the coefficients for each step were examined for significance. The interaction term in step 3 was not significant. Instead, there were significant main effects for both fairness $(B=.62, p<.001)$ and helpfulness $(B=.62, p<.001)$. Although the interaction 
between the helpfulness effect and the fairness effect was not significant, the pattern of helping rate across the conditions is consistent with the nature of the hypothesized interaction.

Specifically, as can be seen in Figure 3, the difference in the rate of helping between participants treated fairly and those treated unfairly was smaller when participants received a helpfulness prime than when they received a control prime. However, the effect was not strong enough to produce the predicted interaction.

\subsection{Descriptive Statistics for Stage 2: The Self-Regulation of OCBs}

Within the sample of 113 participants who made the decision to help (i.e., participants who scored at least one Wonderlic measure), the mean helping effort was $(M=14.32, S D=$ 6.40). The range of measures scored was from one to 30 . Descriptive statistics for helping effort within each condition are presented in Table 4.

\subsection{Stage 2 Hypotheses}

To test for mean differences in helping effort, $t$-test contrasts were made between the fair and unfair conditions and between the helpfulness prime and control prime conditions. Onetailed contrasts were used. Hypothesis 4 predicted that there would be a main effect for fairness perceptions such that helping participants who were treated fairly would score more tests than helping participants who were treated unfairly. Levene's statistic for the contrast between the fair and unfair conditions was not significant, $(p>.05)$, thus equal variances were assumed. The contrast between the fair and unfair conditions was not significant $(t(111)=-0.12, p>.05,1$ tailed), suggesting that those treated fairly $(M=14.38, S D=6.21)$ did not score more tests than those treated unfairly $(M=14.23, S D=6.77)$. Hypothesis 5 predicted that there would be a main effect for priming a helpfulness schema such that participants primed to be helpful would exert more effort than participants not primed with helpfulness. Levene's statistic for the contrast 
between the helpfulness prime and the control prime conditions was not significant, $(p>.05)$, thus equal variances were assumed. The contrast between the helpfulness and control conditions was significant $(t(111)=-1.73, p<.05,1$-tailed $)$ with the helpfulness schema mean $(M=15.11$, $S D=6.22)$ being higher than the control schema mean $(M=12.98, S D=6.57)$, with an effect size of $(d=.34)$. Hypothesis 6 predicted that activating a helpfulness schema would moderate the effects of fairness perceptions for helping participants such that the helpfulness prime effect would be stronger when participants were treated unfairly than when participants were treated fairly. Results of hierarchical multiple regression revealed support for Hypothesis 6 (see Table 5 and Figure 4). Specifically, the interaction term between the fairness of condition and the prime of the condition contributed a significant increment in $R^{2}\left(\Delta R^{2}=0.10, F(3,109)=5.43\right)$. Figure 4 provides a graphic representation of the 2 (Helpfulness) x 2 (Fairness) interaction. As predicted, the helpfulness prime had a stronger effect on participants treated unfairly than those treated fairly. Contrasts for this interaction revealed that within the control prime, participants treated fairly $(M=14.93)$ scored more tests $(t(40)=3.19, p<.01,2$-tailed $)$ than participants treated unfairly $(M=8.62)$. Meanwhile, within the helpfulness prime, contrasts revealed that participants who were treated unfairly scored more tests $(M=16.58)$ than participants treated fairly $(M=$ 13.98). This contrast approached significance $(t(69)=-1.78, p<.10,2$-tailed $)$. An analysis of simple effects that retained the total degrees of freedom yielded the same results as these contrasts.

\subsection{Summary of Results}

The pattern of results for the decision to help was consistent with Hypotheses 1 and 2 such that participants decided to help at a lower rate when treated unfairly and at a greater rate when primed with helpfulness. Although the interaction between the helpfulness effect and the 
fairness effect was not significant, the differences trended in the pattern predicted in Hypothesis 3 (see Figure 3).

Once participants made the decision to help, their self-regulation of effort depended on the interactive effects of the helpfulness prime and the equity effects. Although the main effect for the helpfulness prime (Hypothesis 5) was statistically supported, this effect is not directly interpretable as it was only observed within the inequity condition. As such, helping effort can only be interpreted as a function of the interaction between helpfulness and fairness. The main effect for equity manipulation (Hypothesis 4) was not supported because the equity effect was reversed by the helpfulness prime (i.e., Hypothesis 6 was strongly supported)! In fact, both the minimum and maximum number of tests scored by participants in the inequity condition was higher than the other three conditions. Although the helpers in the helpful prime-unfair condition did not score significantly more tests than helpers in the helpful prime-fair condition, this reversal of the equity effect is impressive, and shows the importance of always studying OCBs using a person by situation approach.

\section{DISCUSSION}

The overarching purpose of this study was to examine the utility of explaining OCBs from an interactionist perspective in both the decision phase to engage in OCBs and the selfregulation phase of the OCB. Previous research on OCBs has focused primarily on main effect explanations; this study sought to demonstrate that such research is deficient. My argument is not that OCBs are always necessarily caused by interactive effects, but tests for interactive effects should always be included in OCB research. I designed an experiment as an OCB analog to the workplace. OCBs were evaluated as a more general form of helping behaviors or prosocial behaviors (Brief \& Motowidlo, 1986). Overall, the results of the present study are congruent 
with others who have found evidence for interactive person-situation effects on OCBs (e.g., Joireman et al., 2006 and Kamdar et al., 2006). These findings not only have compelling implications for conducting future research on OCBs, but also support the development of a social cognitive model of OCBs (Hauenstein \& Kalanick, 2008).

\subsection{Interpretation of Stage 1 Results}

\subsubsection{Helpfulness}

The results of Stage 1 are consistent with previous research demonstrating that priming a trait or stereotype leads to concomitant behavior (Dijksterhuis \& Bargh, 2001; Macrae \& Johnston, 1998; Wheeler \& Petty, 2001). Specifically, participants primed with trait helpfulness decided to help at a greater rate than participants experiencing a control prime. This result is explained by overlap between knowledge structures of perceptions of trait-constructs and knowledge structures for corresponding behavioral tendencies (Bargh et al., 1996; Dijksterhuis \& Bargh, 2001; Wheeler \& Petty, 2001). Thus, given that most people have a mentalrepresentation of what it means to be helpful and to perform helpful behaviors (Macrae \& Johnston, 1998), when this mental structure was made highly accessible through priming, it increased the probability that this knowledge structure (and not another equally applicable knowledge structure) was activated during the opportunity to help. In a parallel manner, employees who have a helpful schema at the forefront of their mind would be expected to be more likely to respond to opportunities to help.

\subsubsection{Equity}

The results of Stage 1 are also consistent with equity theory as participants treated unfairly helped at a lower rate than participants treated fairly. In inequitable situations, equity theory postulates that the saliency of unfair exchange will result in feelings of tension and 
distress, which will be remedied by an accompanying withholding of inputs (Adams, 1965; Huseman, Hatfield, \& Miles, 1987). In the present study, this input took the form of prosocial behaviors, which participants had complete control over the decision to perform. Leventhal (1976) argued that when people are deciding upon inputs to change in an exchange relationship, they not only take into account the control that they have over changing the inputs, but also the costs and risks associated with altering them. In the present study, participants in the inequity group could have gotten angry and just left during the 15 minutes, or demanded that their data be withdrawn from the study, but they were probably unsure if these reactions would have resulted in them losing all credit, or another aversive penalty (Schnake et al., 1995). However, an action that they had complete control over with no associated risks was the decision to score tests and help versus doing a personal activity like reading comics, or completing puzzles. Scoring measures was a likely input to withhold/alter for participants in the inequity group, and in comparison with the fair group, they did. As applied to the workplace, employees who have been treated unfairly would be less likely to respond to helping opportunities than those treated fairly.

\subsubsection{Helpfulness and Fairness Interaction}

Although the predicted interaction was not significant, visual inspection of this relationship supports that the trend is consistent with my prediction (Figure 3). Specifically, the helpfulness prime had a more robust effect for participants treated unfairly than for participants treated fairly. It must be emphasized that the effect of the helpfulness prime was comparable to the effect of the equity manipulation. This finding was not expected; if the prime effect had not been so strong, the interaction would have likely occurred. That being said, the differing pattern of results for Stage 1 and Stage 2 again supports the argument by Hauenstein and Kalanick 
(2008) that the decision processes involved in engaging in an OCB should be researched separately from the self-regulation of OCBs.

\subsection{Interpretation of Stage 2 Results}

\subsubsection{Helpfulness and Equity}

Within the sample of participants who made the decision to help, results did not support a main effect for the equity of condition. Although there was a statistically significant main effect for the helpfulness prime, it is not directly interpretable due to the presence of an interaction effect. Specifically, the helpfulness prime reversed the equity effect, resulting in a significant interaction effect. The expected equity effect was found for participants in the control prime conditions. Not only did this equity effect disappear in the helpful prime condition, but the trend was for participants in the unfair condition to expend greater effort than participants in the fair condition! Kalanick and Hauenstein (2007a) also found that helpers in an inequitable condition helped more than helpers in an equitable condition, making it unlikely that the reversal seen in the current study is a fluke.

The most likely explanation of why helpers in the unfair condition expend them most effort likely involves dissonance reduction (Festinger, 1957). Specifically, participants who were primed with helpfulness experienced tension when they were treated unfairly (a behavior that contradicts helpfulness thoughts) and as a result, they wanted to remedy this tension by aligning their behavior with their salient helpful thoughts. Thus, they overcompensated their helping effort.

\subsection{Summary and Implications for Research}

The results of the present study are consistent with others who argue for an interactionist approach towards OCBs (e.g., Messer \& White, 2006; Joireman et al., 2006; Kamdar et al., 
2006). As opposed to focusing solely on main effect explanations, research is encouraged to increase attention afforded towards uncovering interactive relationships. As such, more studies need to be conducted that explicitly test for statistical interactions. As mentioned above, it is not the expectation that interactions will occur between every combination of variables. However, for those combinations of variables where interactions are reliably occurring, it is inappropriate to only test for main effects.

In a similar manner, increased attention should be afforded to understanding the dynamic interplay between various person and situation variables, specifically, the process by which situational effects on OCBs become internalized and transmuted into internal person-effects on OCBs (e.g., Ehrhart \& Naumann, 2004; Penner et al., 1997).

Additionally, the observation that main effects occurred for the decision to help, while an interactive effect occurred for regulation of helping effort supports that research should investigate antecedents of the decision to engage in an OCB as a separate process from the selfregulation of OCB behavior. As such, more research attention needs to be afforded to understanding the self-regulation of OCB behaviors. To my knowledge, no studies seek to disentangle the intricacies underlying how a person increases, decreases, or ceases OCBs. In tangent, research has neglected the self-regulation of means substitution for OCBs. Specifically, individuals can strive to achieve some desired OCB end state by retaining the same goal but by changing the behaviors used to attain the goal. Shah and Kruglanski (2000) use the label 'means substitution' to describe the fact that "goals have the property of equifinality: that is, they typically can be attained through a number of different actions" (p. 88).

The empirical evidence of a distinction between the decision to help and the regulation of helping behavior in addition to the interactive effects discussed above provide support for the 
two-stage social cognitive model of OCBs proposed by Hauenstein \& Kalanick (2008). Through incorporating interactive effects, this model enables a more holistic depiction of the array of antecedents of OCBs versus the current person-situation taxonomy, where the emphasis is on explanation-competition, instead of explanation-complementation.

The existing person-situation taxonomy for organizing the myriad of antecedents of OCBs has numerous limitations that obstruct progress in understanding OCBs. For one, the dichotomous nature of the person-situation taxonomy encourages research that combats these categories in pursuit of broad generalizations. As such, findings for main effect models are likely to be over-generalized. For example, helping cues that instigate formation/recall of fairness perceptions (i.e., equity effects) is a very potent situational explanation of OCBs. Yet, for the self-regulation of OCB effort, I was able to reverse the equity effect by priming helpfulness. Unfairness will not always lead to less helping effort in all OCB contexts! Second, the taxonomy has failed to disentangle the processes responsible for the decision to engage in an OCB from those responsible for self-regulation of the OCB. In light of these issues, I tested for an interaction between a person and situation effects separately for both the decision to help and the self-regulation of that helping behavior. Results not only supported a distinction between these two phases, but also supported an interaction. As such, I agree with others that more interactive studies are warranted, and that the development of a 2-stage social cognitive model of OCBs by Hauenstein \& Kalanick (2008) is justified. 


\section{REFERENCES}

Adams, J.S.(1965). Inequity in social exchange. In L. Berkowitz (Ed.), Advances in Experimental Psychology, vol.2, pp. 267-299. New York: Academic Press.

Bargh, J.A., Chen, M., \& Burrows, L.(1996). Automaticity of social behavior: Direct effects or trait construct and stereotype activation on behavior. Journal of Personality and Social Psychology, 71, 230-244.

Bateman, T.S., \& Organ, D.W. (1983). Job satisfaction and the Good Soldier: The Relationship between Affect and Employee "Citizenship." Academy of Management Journal, 26, 587-595.

Blau, P. (1964). Exchange and power in social life. New York: Wiley.

Borman, W.C., \& Motowidlo, S.J. (1993). Expanding the criterion domain to include elements of contextual performance. In N. Schmitt \& W.C. Borman (eds.), Personnel selection in organizations. San Francisco: Jossey-Bass.

Borman, W.C., \& Motowidlo, S.J. (1997). Task performance and contextual performance: The meaning for personnel selection research. Human Performance, 10, 99-109.

Brief, A.R., \& Motowidlo, S.J. (1986). Prosocial organizational behaviors. Academy of Management Review, 11, 710-725.

Cardona, P., Lawrence, B.S., \& Bentler, P.M. (2004). The influence of social and work exchange relationships on organizational citizenship behavior. Group and Organization Management, 29, 219-247.

Carver, C.S., \& Scheier, M.F. (1982). Control theory: A useful conceptual framework for personality-social, clinical, and health psychology. Psychological Bulletin, 92, 111-135. 
Carver, C.S. \& Scheier, M.F. (1990). Origins and functions of positive and negative affect: A control-process view. Psychological Review, 97, 19-35.

Coyle-Shapiro, J.A-M. (2002). A psychological contract perspective on organizational citizenship behavior. Journal of Organizational Behavior, 23, 927-946.

Deci, E.L. (1972). The effects of contingent and noncontingent rewards and controls on intrinsic motivation. Organizational Behavior and Human Performance, 8, 217-229.

Deci, E.L., Benware, C., \& Landy, D. (1974). The attribution of motivation as a function of output and rewards. Journal of Personality, 42, 652-667.

Dijksterhuis, A., Aarts, H., Bargh, J.A., \& van Knippenberg, A. (2000). On the relation between associative strength and automatic behavior. Journal of Experimental Social Psychology, $36,531-544$.

Dijksterhuis, A., \& Bargh, J.A. (2001). The perception-behavior expressway: Automatic effects of social perception on social behavior. Advances in Experimental Social Psychology, 33, $1-40$.

Dijksterhuis, A., Spears, R., \& Lepinasse, V. (2001). Reflecting and deflecting stereotypes: Assimilation and contrast in impression formation and automatic behavior. Journal of Experimental Social Psychology, 37, 286-299.

Dijksterhuis, A., \& van Knippenberg, A. (1998). The relation between perception and behavior, or how to win a game of Trivial Pursuit. Journal of Personality and Social Psychology, $74,865-877$.

Dineen, B.R., Lewicki, R.L., \& Tomlinson, E.C. (2006). Supervisory guidance and behavioral integrity: Relationships with employee citizenship and deviant behavior. Journal of Applied Psychology, 91, 622-635. 
Ehrhart, M.G., \& Naumann, S.E. (2004). Organizational citizenship behavior in work groups: A group norms approach. Journal of Applied Psychology, 89, 960-974.

Farh, J.L., Podsakoff, P.M., \& Organ, D.W. (1990). Accounting for organizational citizenship behavior: leader fairness and task scope versus satisfaction. Journal of Management, 16, $705-721$.

Festinger, L.(1957). A theory of cognitive dissonance. Stanford, CA: Stanford University Press.

Finkelstein, M.A., \& Penner, L.A. (2004). Predicting organizational citizenship behavior: Integrating the functional and role identity approaches. Social Behavior and Personality, 32, 383-398.

Gagne, M. \& Deci, E.L. (2005). Self-determination theory and work motivation. Journal of Organizational Behavior, 26, 331-362.

George, J.M. (1991). State or Trait: Effects of positive mood on prosocial behaviors at work. Journal of Applied Psychology, 76, 299-307.

Goldberg, L.R. (1999). A broad-bandwidth, public domain, personality inventory measuring the lower-level facets of several five-factor models. In I. Mervielde, I. Deary, F. De Fruyt, \& F. Ostendorf (Eds.), Personality Psychology in Europe, Vol. 7 (pp. 7-28). Tilburg, The Netherlands: Tilburg University Press.

Hauenstein, N.M.A \& Kalanick, J. (2008). A Two-Stage Model of Organizational Citizenship Behaviors. Unpublished Manuscript.

Higgins, E.T., Rholes, W.S., \& Jones, C.R. (1977). Category accessibility and impression formation. Journal of Experimental Social Psychology, 13, 141-154. 
Higgins, E.T. (1996). Knowledge activation: Accessibility, applicability, and salience. In E.T. Higgins \& A.W. Kruglanski (Eds.), Social Psychology: Handbook of basic principles, pp. 133-169. New York: Guilford Press.

Higgins, E.T. (1999). Persons and situations: unique explanatory principles or variability in general principles. In D. Cervone \& Y. Shoda (Eds.), The Coherence of Personality: Social-Cognitive Bases of Consistency, Variability, and Organization, pp. 61-93. Guilford: New York.

Hoffman, B.J., Blair, C.A., Meriac, J.P., \& Woehr, D.J. (2007). Expanding the criterion domain? A quantitative review of the OCB literature. Journal of Applied Psychology, 92, 555-566.

Huseman, R.C., Hatfield, J.D., \& Miles, E.W. (1987). A new perspective on equity theory: The equity sensitivity construct. Academy of Management Review, 12, 222-234.

International Personality Item Pool. (2001). A Scientific Collaboratory for the Development of Advanced Measures of Personality Traits and Other Individual Differences (http://ipip.ori.org/). Internet Web Site.

Joireman, J., Kamdar, D., Daniels, D., \& Duell, B. (2006). Good citizens to the end? It depends: Empathy and concern with future consequences moderate the impact of a short-term horizon on organizational citizenship behaviors. Journal of Applied Psychology, 91, 1307-1320.

Katz, D., \& Kahn, R.L. (1966). The social psychology of organizations. New York: Wiley. Kalanick, J., \& Hauenstein, N.M.A. (2007a, May). Antecedents of Organizational Citizenship Behaviors. Paper presented at the nineteenth annual meeting of the Association for Psychological Science, Washington, DC. 
Kalanick, J. \& Hauenstein, N.M.A. (2007b). [Effects of intrinsic and extrinsic motivation and fairness on helping]. Unpublished raw data.

Kamdar, D., McAllister, D.J., \& Turban, D.B. (2006). “All in a day’s work”: How follower individual differences and justice perceptions predict OCB role definitions and behavior. Journal of Applied Psychology, 91, 841-855.

King, E.B., George, J.M., \& Hebl, M.R. (2005). Linking personality to helping behaviors at work: An Interactional perspective. Journal of Personality, 73, 585-607.

King, W.C. \& Miles, E.W. (1994). The measurement of equity sensitivity. Journal of Occupational and Organizational Psychology, 67, 133-142.

Konovsky, M.A., \& Organ, D.W. (1996). Dispositional and contextual determinants of organizational citizenship behavior. Journal of Organizational Behavior, 17, 253-266.

Konovsky, M.A., \& Pugh, S.D. (1994). Citizenship behavior and social exchange. Academy of Management Journal, 37, 656-669.

Lee, K., \& Allen, N.J. (2002). Organizational citizenship behavior and workplace deviance: The role of affect and cognitions. Journal of Applied Psychology, 87, 131-142.

Leventhal, G.S. (1976). Fairness in social relationships. In Thibaut, J. W., Spence, J. T., \& Carson, R.C. (eds.), Contemporary topics in social psychology, pp. 211-239. New Jersey: General Learning.

Macrae, C.N., \& Johnston, L. (1998). Help, I need somebody: Automatic action and inaction. Social Cognition, 4, 400-417.

Mischel, W. (2004). Toward an integrative science of the person. Annual Review of Psychology, $55,1-22$. 
Mischel, W., \& Shoda, Y. (1995). A cognitive-affective system theory of personality; Reconceptualizing situations, dispositions, dynamics, and invariance in person structure. Psychological Review, 102, 246-268.

Mischel, W., \& Shoda, Y. (1998). Reconciling processing dynamics and personality dispositions. Annual Review of Psychology, 49, 229-258.

Messer, B.A., \& White, F.A. (2006). Employees' mood, perceptions of fairness, and organizational citizenship behavior. Journal of Business and Psychology, 21, 65-82.

Moorman, R.H. (1993). The influence of cognitive and affective based job satisfaction measures on the relationship between satisfaction and organizational citizenship behavior. Human Relations, 46, 759-766.

Motowidlo, S.J. (1984). Does job satisfaction lead to consideration and personal sensitivity? Academy of Management Journal, 27, 910-915.

Netemeyer, R.G., Boles, J.S., McKee, D.O., \& McMurrian, R. (1997). An investigation into the antecedents of organizational citizenship behaviors in a personal selling context. Journal of Marketing, 61, 85-98.

Neuman, G.A., \& Kickul, J.R. (1998). Organizational citizenship behaviors: Achievement orientation and personality. Journal of Business and Psychology, 13, 263-279.

Olkkonen, M., \& Lipponen, J. (2006). Relationships between organizational justice, identification with organization and work unit, and group-related outcomes. Organizational Behavior and Human Decision Processes, 100, 202-215.

Organ, D.W. (1988). A restatement of the satisfaction-performance hypothesis. Journal of Management, 14, 547-557. 
Organ, D.W. (1997). Organizational citizenship behaviors: It's construct clean-up time. Human Performance, 10, 85-97.

Organ, D.W., \& Konovsky, M. (1989). Cognitive versus affective determinants of organizational citizenship behavior. Journal of Applied Psychology, 74, 157-164.

Organ, D.W., \& Lingl, A. (1995). Personality, satisfaction, and organizational citizenship behavior. The Journal of Social Psychology, 135, 339-350.

Organ, D.W., \& Ryan, K. (1995). A meta-analytic review of attitudinal and dispositional predictors of organizational citizenship behavior. Personnel Psychology, 48, 775-802.

Penner, L.A., Midili, A.R., \& Kegelmeyer, J. (1997). Beyond job attitudes: A personality and social psychology perspective on the causes of organizational citizenship behavior. Human Performance, 10, 111-131.

Podsakoff, P.M., MacKenzie, S.B., Paine, J.B., \& Bachrach, D.G. (2000). Organizational citizenship behaviors: A critical review of the theoretical and empirical literature and suggestions for future research. Journal of Management, 26, 513-563.

Rioux, S.M., \& Penner, L.A. (2001). The causes of organizational citizenship behavior: A motivational analysis. Journal of Applied Psychology, 86, 1306-1314.

Schappe, S.P. (1998). The influence of job satisfaction, organizational commitment, and fairness perceptions on organizational citizenship behavior. The Journal of Psychology, 132, 277-290.

Schnake, M., Cochran, D., \& Dumler, M. (1995). Encouraging organizational citizenship: The effects of job satisfaction, perceived equity and leadership. Journal of Managerial Issues, 7, 209-221. 
Shah, J.Y., \& Kruglanski, A.W. (2000). Aspects of goal networks: Implications for selfregulation. In M. Boekaerts, P. R. Pintrich, \& M. Zeidner (Eds.), Handbook of selfregulation (pp. 85-110). San Diego, CA: Academic Press.

Srull, T.K., \& Wyer, R.S. (1979). The role of category accessibility in the interpretation of information about persons: Some determinants and implications. Journal of Personality and Social Psychology, 37, 1660-1672.

Smith, C.A., Organ, D.W., \& Near, J.P. (1983). Organizational Citizenship Behavior: Its Nature and Antecedents. Journal of Applied Psychology, 68, 653-663.

Vey, M.A., \& Campbell, J.P. (2004). In-role or extra-role organizational citizenship behavior: Which are we measuring? Human Performance, 17, 119-135.

Wagner, S.L., \& Rush, M.C. (2000). Altruistic organizational citizenship behavior: Context, disposition, and age. The Journal of Social Psychology, 140, 379-391.

Watson, D., Clark, L.A., \& Tellegen, A. (1988). Development and validation of brief measures of positive and negative affect: The PANAS scales. Journal of Personality and Social Psychology, 54, 1063-1070.

Watt, D., \& Shaffer, M.A. (2005). Equity and relationship quality influences on organizational citizenship behaviors. Personnel Review, 34, 406-422.

Wheeler, S.C., \& Petty, R.E. (2001). The effects of stereotype activation on behavior: A review of possible mechanisms. Psychological Bulletin, 127, 797-826.

Williams, L.J., \& Anderson, S.E. (1991). Job satisfaction and organizational commitment as predictors of organizational citizenship and in-role behaviors. Journal of Management, 17, 601-617. 


\section{APPENDICES}




\subsection{Appendix A: Informed Consent Form}

\section{VIRGINIA POLYTECHNIC INSTITUTE \& STATE UNIVERSITY}

\section{INFORMED CONSENT DOCUMENT: Adult Consent Form}

STUDY TITLE: Exploring the Relationship between Personality and Judgments about Corrective Action for Juvenile Delinquents

PRINCIPAL INVESTIGATOR: Julie Kalanick, M.S., Dept. of Psychology

Purpose of the Study

The research study is aimed at evaluating how personality variables relate to judgments about corrective action for juvenile delinquents.

Approximately 150 undergraduate students from Virginia Tech will be recruited for this experiment, which will take approximately 2-3 hours. Please note that only students age 18 or older are eligible to participate in this study.

This study is being conducted by Julie Kalanick, M.S., who is a graduate student in Virginia Tech's Industrial/Organizational Psychology program. If you have any questions about this study, please feel free to contact any of the following individuals:

Julie Kalanick: (540) 250-2632 or juliek2@vt.edu

Dr. Neil Hauenstein: (540) 231-5716 or nhauen@vt.edu

Dr. Robert Stephens, Chair Psychology Department : (540) 231-6304 or stephens@vt.edu

Dr. David Harrison, Chair HSC: (540) 231-4422

Dr. David Moore, Chair IRB: (540) 231-4991 or moored@vt.edu

\section{Procedure to be Followed}

You have registered for this study through the Sona System, the Department of Psychology's online Experiment Management System. You have been given an online link that contains an Informed Consent Form and Phase 1 measures. You attest that you will read through this Informed Consent form prior to participating in Phase 1. You acknowledge that you will receive a hard-copy of this form to sign at Phase 2, and the Informed Consent process will be discussed with you.

After reading and consenting to the online Informed Consent form, you will complete Phase 1. During phase one of the study, you will fill out three measures and schedule a timeslot for phase 2. This should take approximately one hour of your time.

At Phase 2 of this study, you will be given a copy of this Informed Consent form to sign and the opportunity to ask questions. Then, you will be provided with five concise vignettes to read, which are anonymous case studies describing various offenses of juvenile delinquents. You will be asked to first write what you believe may have caused the person's current behavior, and second, to envision yourself as a correction officer and to write what you believe is the appropriate intervention or course of action needed to be taken towards each delinquent. Your goal as the correction officer will be to suitably reprimand the delinquent and to educate the delinquent on the inappropriateness of his/her actions, and to assist the delinquent in engaging in more socially acceptable ways of behavior. You will be given 1 hour to do this task, and are required to write at least one page for each of the five case studies. Phase 2 will take approximately two hours of your time.

\section{Anonymity of Subjects}

The results of this study will be kept strictly confidential. The information you provide will have your name removed and number will be used to identify you when we look at the information you have provided. The information obtained in this project may be used for scientific or educational purposes. It may be presented at scientific meetings and/or published and reproduced in professional journals, books, or used for any other purpose 
that Virginia Tech's Department of Psychology considers proper in the interest of education, dissemination of knowledge, or research. However, information collected will not be presented in any manner that will identify you or anyone else by name.

\section{Discomforts and Risks from Participating in This Study}

There should be no more than minimal risks to you from participation in this study. There may be deception used in this study. There may be portions of this study where you may experience mild emotional distress or anxiety. However, any anxiety experienced will be transitory and will only last for a small portion of the study. We are required by the institutional review board (who oversees the informed consent process) to inform you that in the extremely unlikely case that you desire professional counseling due to the effects of this study, we will provide you with contact information. However, your use of professional counseling is at your own expense.

\section{Benefits of the Project}

The personal benefit of this study is that it exposures you to various measures that you may encounter in various job selection test batteries. Further, you will explore your personal views regarding corrective action for juvenile delinquents. There are additional benefits, but they cannot be fully described to you at this time. However, they will be described to you following completion of your participation.

\section{Freedom to Withdraw}

Your participation in this study is completely voluntary. If you choose to participate, you may withdraw from the study at any time without penalty. You do not have to answer any questions that make you feel uncomfortable. You may stop answering questions at any time you choose.

\section{Compensation}

You may earn up to three extra credit points towards a Psychology class you are enrolled in, that is listed on the Sona System. Note that if you choose not to participate, there may be other opportunities to accrue extra-credit points from other studies, or activities.

\section{Subject Permission}

I have read and understand the description of the study. I have had an opportunity to ask questions and to have them answered. I hereby acknowledge the above and give my voluntary consent for participation in this study. I further understand that I may withdraw at any time with out penalty. I understand that I can have any questions regarding this research and its conduct answered for me.

Print your Name 


\section{Instructions for Administering the PANAS items}

The scale below has 20 words that represent different feelings and emotions. Carefully read each item, and consider to what extent you generally feel that way, that is, how much you feel that way on average. Use the following 5-point scale to represent your average feeling for each item, and select the number that corresponds to the number on the scale for each item. Please answer as honestly as possible. Your responses will be kept in strict confidence.

$\begin{array}{ccccc}1 & 2 & 3 & 4 & 5 \\ \text { Very slightly } & \text { a little } & \text { moderately } & \text { quite a bit } & \text { extremely } \\ \text { Or not at all } & & & \end{array}$
1) Interested
2) Distressed
3) Excited
4) Upset
5) Strong
6) Guilty
7) Scared
8) Hostile
9) Enthusiastic
10) Proud
11) Irritable
12) Alert
13) Ashamed
14) Inspired
15) Nervous
16) Determined
17) Attentive
18) Jittery
19) Active
20) Afraid 


\subsection{Appendix C: The ESI}

\section{Instructions for Administering the ESI}

\section{HOW YOU FEEL ABOUT ORGANIZATIONS IN GENERAL}

The questions on this inventory ask what you'd like for your relationship to be with any organization for which you might work. On each question, divide 10 points between the two answers (A and B) by giving the most points to the choice that is most like you and the fewest

points to the choice that is least like you. You can, if you'd like, give the same number of points to both answers. You may use zeros if you'd like.

Just be sure to use all 10 points on each question. Place your points into the blank next to each letter.

\section{IN ANY ORGANIZATION I MIGHT WORK FOR:}

1. It would be more important for me to:

A. Get from the organization

B. Give to the organization

2. It would be more important for me to:

A. Help others

B. Watch out for my own good

3. I would be more concerned about:

A. What I received from the organization

B. What I contributed to the organization

4. The hard work I would do should:

A. Benefit the organization

B. Benefit me

5. My personal philosophy in dealing with the organization would be:

A. If I don't look out for myself, nobody else will

B. It's better for me to give than to receive 


\subsection{Appendix D: The IPIP}

\section{Instructions for Administering the IPIP items}

On the following pages, there are phrases describing people's behaviors. Please use the rating scale below to describe how accurately each statement describes you. Describe yourself as you generally are now, not as you wish to be in the future. Describe yourself as you honestly see yourself, in relation to other people you know of the same sex as you are, and roughly your same age. So that you can describe yourself in an honest manner, your responses will be kept in absolute confidence. Please read each statement carefully.

\section{Response Options}

1: Very Inaccurate

2: Moderately Inaccurate

3: Neither Inaccurate nor Accurate

4: Moderately Accurate

5: Very Accurate

1) Am the life of the party.

2) Insult people.

3) Am always prepared.

4) Get stressed out easily.

5) Have a rich vocabulary.

6) Often feel uncomfortable around others.

7) Am interested in people.

8) Leave my belongings around.

9) Am relaxed most of the time.

10 Have difficulty understanding abstract ideas

11) Feel comfortable around people.

12) Am not interested in other people's problems

13) Pay attention to details.

14) Worry about things.

15) Have a vivid imagination.

16) Keep in the background.

17) Sympathize with others' feelings.

18) Make a mess of things.

19) Seldom feel blue.

20) Am not interested in abstract ideas.

21) Start conversations.

22) Feel little concern for others.

23) Get chores done right away.

24) Am easily disturbed.

25) Have excellent ideas.

26) Have little to say.

27) Have a soft heart.

28) Often forget to put things back in their place

29) Am not easily bothered by things.

30) Do not have a good imagination.

31) Talk to a lot of different people at parties

32) Am not really interested in others.

1.

2.

3.

4.

5.

6.

7.

8.

9.

10.

11.

12.

13.

14.

15.

16.

17.

18.

19.

20.

21.

22.

23.

24.

25.

26.

27.

28.

29.

30.

31.

32.

33) Like order.

33.

34) Get upset easily.

34. 
35) Am quick to understand things.

35.

36) Don't like to draw attention to myself.

36.

37) Take time out for others.

38) Shirk my duties.

39) Rarely get irritated.

37.

40) Try to avoid complex people.

41) Don't mind being the center of attention.

42) Am hard to get to know.

43) Follow a schedule.

44) Change my mood a lot.

45) Use difficult words.

46) Am quiet around strangers.

47) Feel others' emotions.

48) Neglect my duties.

49) Seldom get mad.

50) Have difficulty imagining things.

38.

39.

40.

41.

42.

43.

44.

45.

46.

47.

48.

49.

50. 


\subsection{Appendix E: Vignettes and Instructions for their Administration}

Below are three case studies of anonymous juvenile-offenders, who have been convicted of a variety of offenses. Please read each case study carefully and for each case study, write at least one full page based on the following two criteria:

a) Use your knowledge of psychology and discuss aspects of childhood or environmental influences that may have encouraged each juvenile delinquent's behavior. You are encouraged to make your own psychological interpretations and theories as well.

b) Describe how each delinquent's current behavior will likely influence their behavior in adulthood.

Please use as much detail as possible. Each case study should take approximately 10 minutes for you to write about; please budget your time accordingly. You have $\mathbf{3 0}$ minutes to complete this task and the researcher will collect your responses only at that time.

Case study \#1:

Subject A is a 16 year-old male who has been convicted of numerous instances of damage to private property. His behaviors include: writing violent and sexually explicit graffiti on elementary schools, school-buses, and residential homes, slashing car-tires and "keying" cars, and setting fire to cars, homes, and landscapes in residential neighborhoods. Subject A maintains that society has rejected him, and therefore, that the rules of society no longer apply.

Case study \#2

Subject B is a 15 year-old female who has been convicted of several drug-related crimes. Subject B's offenses include: theft of mood-inducing medications from a pharmacy (including narcotics and anti-depressants), as well as theft of various 'over-the-counter' medicines, which she has used to make illicit drugs. Subject B has also been involved in the use of Cocaine, LSD, Ecstasy, Crystal-Meth, and Heroin. Subject B states that she needs the altered-state induced by drugs to enjoy her life and to feel good about herself. Subject B claims that she doesn't "fit-in" in school or at home, and that everyone thinks she is a "worthless loser." She states the world is a better place when she is high.

Case study \#3

Subject $C$ is a 16 year-old male who has been involved in gang-warfare activities. His behaviors include knife-fights and other aggressive acts, breaking and entering into residential homes and stealing electronics, and mugging people for cash and credit cards. Subject $\mathrm{C}$ says that since his family rejected him, his gang is his new family and he is willing to do anything to show his loyalty and support. Further, Subject $\mathrm{C}$ says he loves the power he feels as a gang member and the ability to intimidate others. 


\subsection{Appendix F: Helpfulness Prime}

Research has consistently demonstrated that a critical issue with juvenile delinquents is that they do not have a strong desire to help others (e.g., Jones, 2002; Allen, Warren, \& MacKenize, 2003; Cardell \& Smith, 2005; Paloma \& Harris, 2006). Indeed, because juvenile delinquents feel rejected and alienated by society, they don't readily think about helping others and often refrain from helping opportunities (Hood-White \& Osowski, 2006). As a result, psychologists at Virginia Tech are working to design an intervention that will assist juvenile delinquents in understanding the value of helping. We are asking college students to give their perception about what constitutes helpfulness. This data will support an intervention that demonstrates to juvenile delinquents what others in their age-bracket believe about helping.

For this task, we would like you to think about the concept of helpfulness. Please write as many synonyms of helpfulness that you can think of and write the behaviors, values, and lifestyle, of a helpful person.

Please be as detailed as possible.

Please write on a separate sheet of paper.

The researcher will return in 10 minutes to collect your response. 


\subsection{Appendix G: Control Prime}

Research has consistently demonstrated that a critical issue with juvenile delinquents is that they enjoy harassing and angering others (e.g., Jones, 2002; Allen, Warren, \& MacKenize, 2003;

Cardell \& Smith, 2005; Paloma \& Harris, 2006). Indeed, juvenile delinquents often behave in a destructive manner solely to arouse negative feelings in others (Hood-White \& Osowski, 2006). As a result, psychologists at Virginia Tech are interested in understanding young adults' perceptions (e.g., college students) about what constitutes a typical juvenile delinquent.

For this task, we would like you to think about the concept of juvenile delinquency. Please write as many characteristics of juvenile delinquency that you can think of, and write the behaviors, values, and lifestyle, of a typical juvenile delinquent.

Please be as detailed as possible.

Please write on a separate sheet of paper.

The researcher will return in 10 minutes to collect your response. 


\section{The American Psychological Association (APA)}

Title of Experiment: Judgments and Juvenile Delinquency

Primary Researcher: Julie L Kalanick

IRB Approval Number: 07-470

Institution: Virginia Polytechnic Institute and State University, Blacksburg, VA, 24060

Experiment Interval: November 16, 2007 - April 30, 2008

Please read the statement below, and sign in either black or blue ink

The effort that I expended on the specified experiment was fair given the amount of extra credit.

\section{Name}

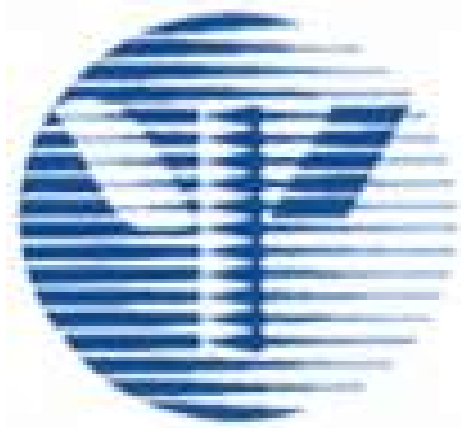


6.9 Appendix I: Unfairness Signature Form

\section{Virginia Polytechnic Institute and State University \\ Department of Psychology \\ Experiment Review Committee}

Title of Experiment: Judgments and Juvenile Delinquency

Primary Researcher: Julie L Kalanick

IRB Approval Number: 07-470

Experiment Interval: November 16, 2007 - April 30, 2008

Please read the statement below, and sign in either black or blue ink

I am aware that the extra credit for the specified experiment has been changed

from 2 extra credit points to 1 extra credit point.

Name

Signature

Date 


\subsection{Appendix J: Debriefing Form for Participants in the Fair Condition}

Please be assured that you will receive two extra credit points for your participation. The true purpose of the experiment was to assess how the situation you were impacted your willingness to help. The true title of this study was, Helping in the Workplace: A Social Cognitive Perspective. In the laboratory, we used different manipulations that affect a person's willingness to help out (i.e., score the Wonderlic measures that were available to you after you completed Tasks 1-3). In our analyses of helping behaviors, we will examine how these manipulations impacted your helpfulness. These details were not given to you earlier to protect against them affecting your behavior.

Note that you are allowed to request that your data be removed from the study without penalty.

We thank you for your participation.

Do you have any questions?

\section{WE ASK THAT YOU REFRAIN FROM TELLING ANY OTHER PARTICIPANTS ABOUT THE DETAILS OF THIS EXPERIMENT, INCLUDING THE USE OF DECEPTION. THIS IS TO ENABLE THE MOST ACCURATE DATA TO BE COLLECTED. THANK YOU!!!}

\section{Contact Information:}

Julie Kalanick: (540) 250-2632 or juliek2@vt.edu

Dr. Neil Hauenstein: (540) 231-5716 or nhauen@vt.edu

Dr. Robert Stephens, Chair Psychology Department : stephens@vt.edu

Dr. David Harrison, Chair HSC: (540) 231-4422

Dr. David Moore, Chair IRB: (540) 231-4991 or moored@vt.edu 


\subsection{Appendix K: Debriefing Form for Participants in the Unfair Condition}

Please be assured that you will be receiving the 2 extra credit points that you were promised. You were told that you would not receive the amount of extra credit that you were promised for participating in this research study. This was deception. We genuinely apologize to you for the use of deception in this experiment and for any feelings of anger or emotional distress that you may have experienced. This deception was necessary, however, because we wanted to see how you would naturally respond to an equitable situation. Your natural behavioral response was essential to the integrity of the data. . If you are experiencing any emotional distress and feel that you are in need of professional counseling, please let us know, or contact one of the people below, and they will put you in touch with a professional counselor. However, any professional counseling that you seek will be at your own expense.

The true purpose of this experiment was to assess how personal and situational variables affect one's enactment of a helping behavior and overall effort expenditure on helping. The true title of this study is, Helping in the Workplace: A Social Cognitive Perspective. In the laboratory, we used different manipulations (such as the unfairness) that affect a person's willingness to help out (i.e., score the Wonderlic measures that were available to you after you completed Tasks 13). In our analyses of helping behaviors, we will examine how these manipulations impacted your helpfulness. These details were not given to you earlier to protect against them affecting your behavior.

Note that you are allowed to request that your data be removed from the study without penalty.

We thank you for your participation.

Do you have any questions?

\section{WE ASK THAT YOU REFRAIN FROM TELLING ANY OTHER PARTICIPANTS ABOUT THE DETAILS OF THIS EXPERIMENT, INCLUDING THE USE OF DECEPTION. THIS IS TO ENABLE THE MOST ACCURATE DATA TO BE COLLECTED. THANK YOU!!!}

\section{Contact Information:}

Julie Kalanick: (540) 250-2632 or juliek2@vt.edu

Dr. Neil Hauenstein: (540) 231-5716 or nhauen@vt.edu

Dr. Robert Stephens, Chair Psychology Department : (540) 231-6304 or stephens@vt.edu

Dr. David Harrison, Chair HSC: (540) 231-4422

Dr. David Moore, Chair IRB: (540) 231-4991 ormoored@vt.edu 


\section{FIGURES}


Figure 1. Stage 1: The Decision to Engage in an OCB

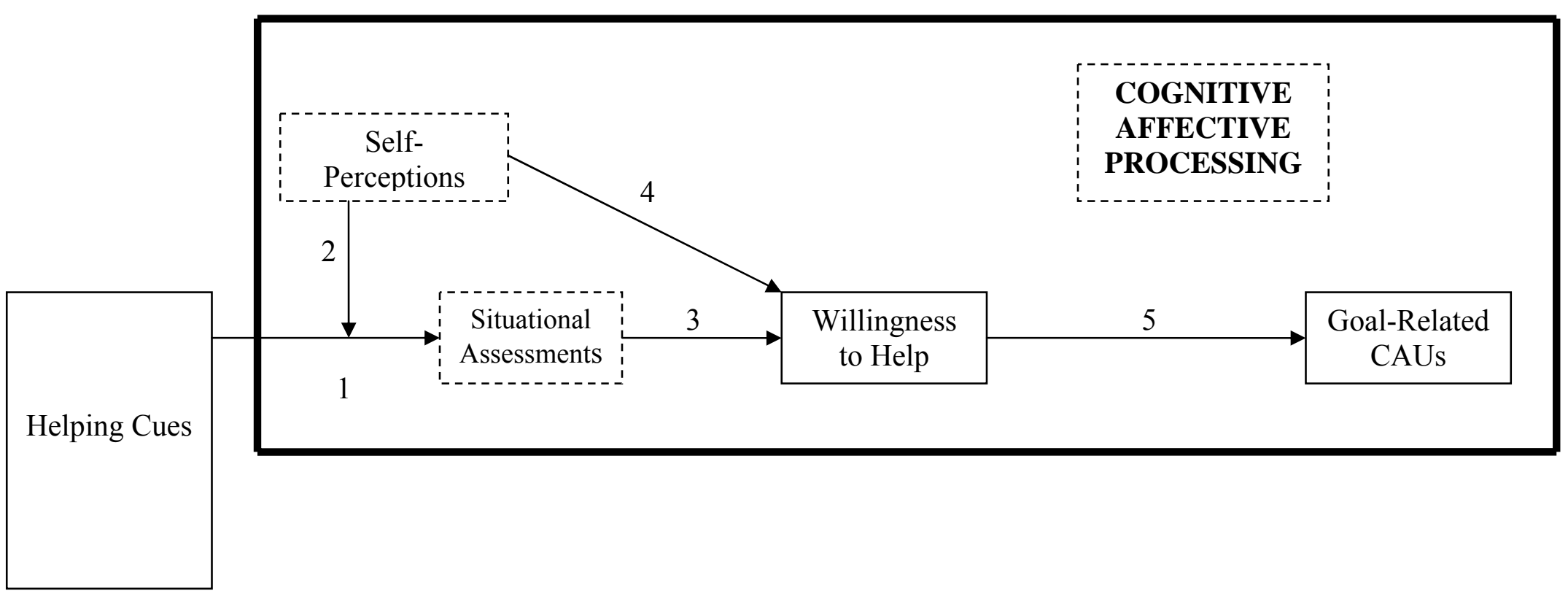

Figure 1. Cognitive-affective processing of a given set of helping cues via situational assessments and self-perceptions establishes a situation-specific willingness to help for each individual. Willingness to help is converted to goal-related CAUs through self-

regulatory processes. 
Figure 2. Stage 2: Self-Regulation of Superordinate OCB Goals

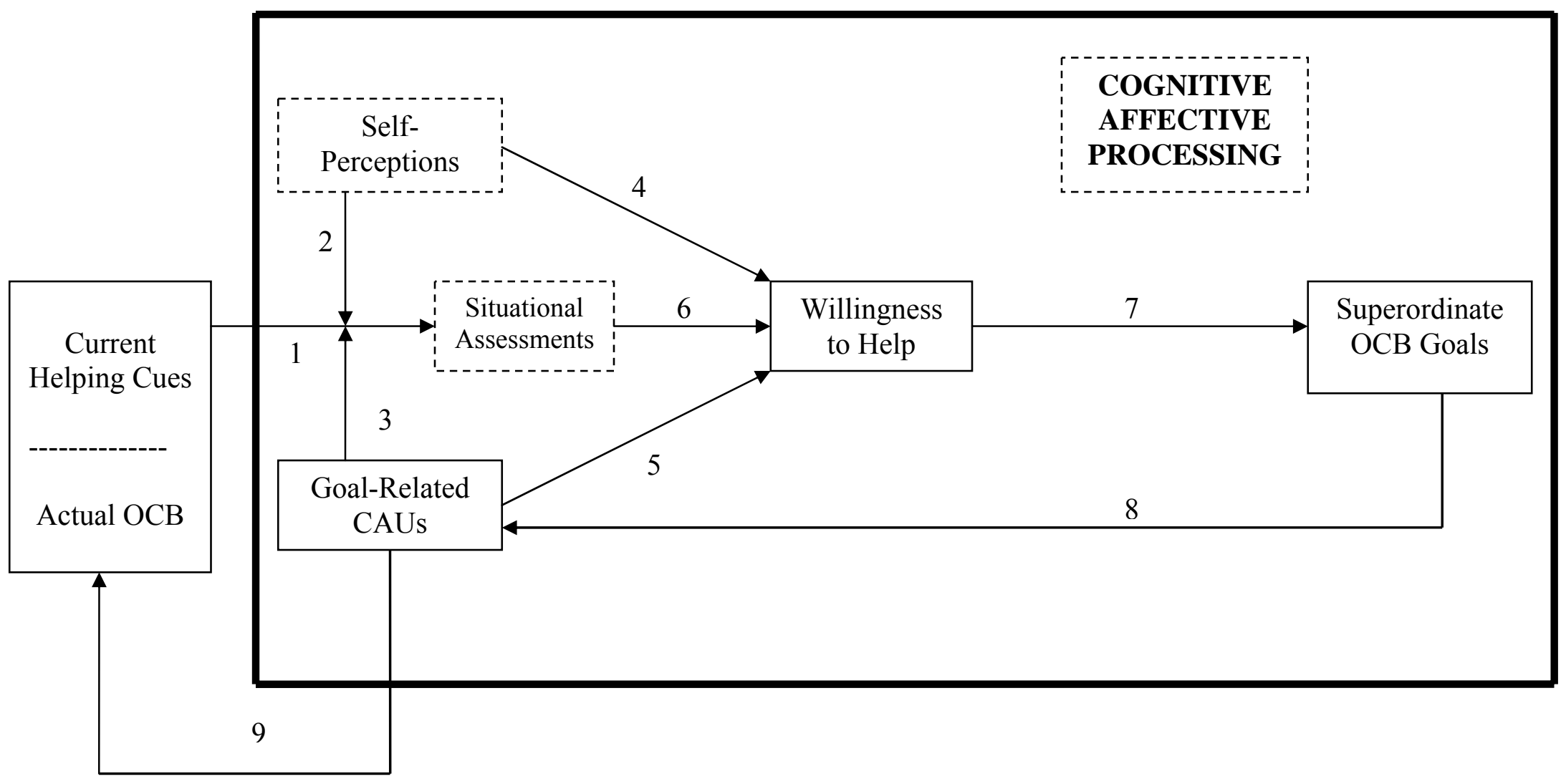

Figure 2. Available helping cues and helping behavior initiate the cognitive-affective processing which now includes the influence of goal-related CAUs. A bi-level self-regulation system results in a decision to continue or cease the OCB that best reduces discord between willingness to help and the helping threshold. 
Figure 3. Helping Rate for the 2 (Helpfulness) x 2 (Fairness) design $(\mathrm{N}=194)$

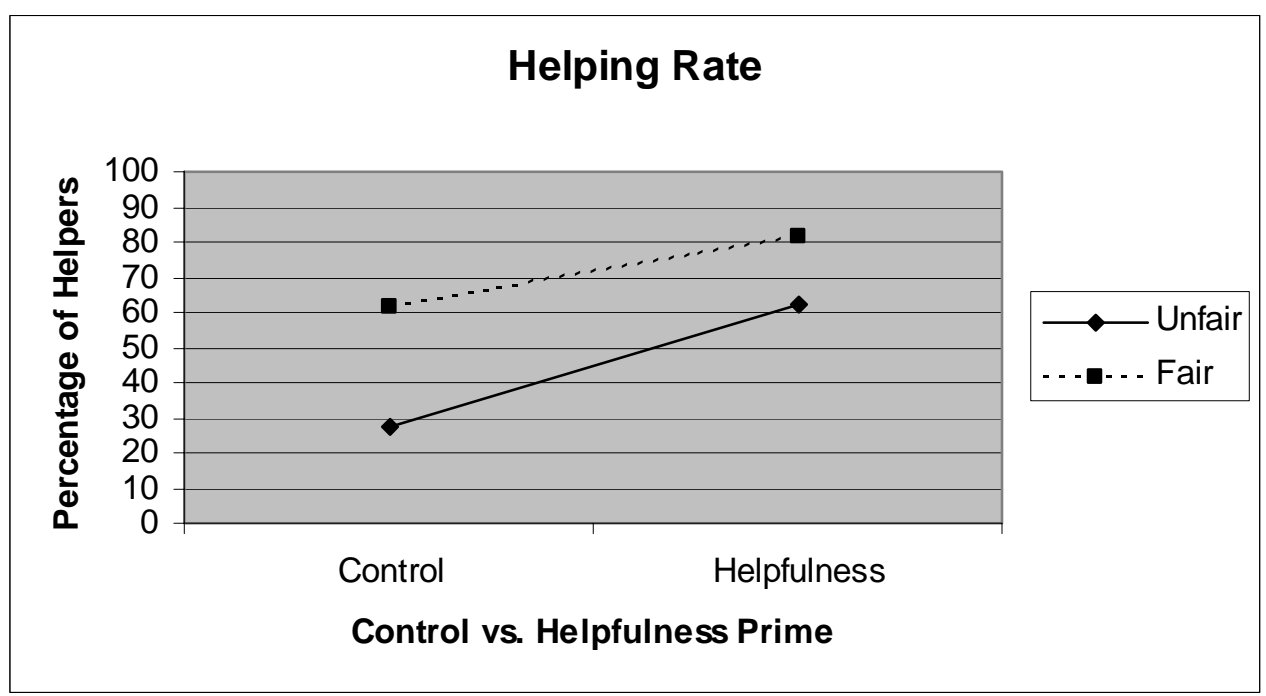


Figure 4. Mean Helping Effort for the 2 (Helpfulness) x 2 (Fairness) design $(n=133)$

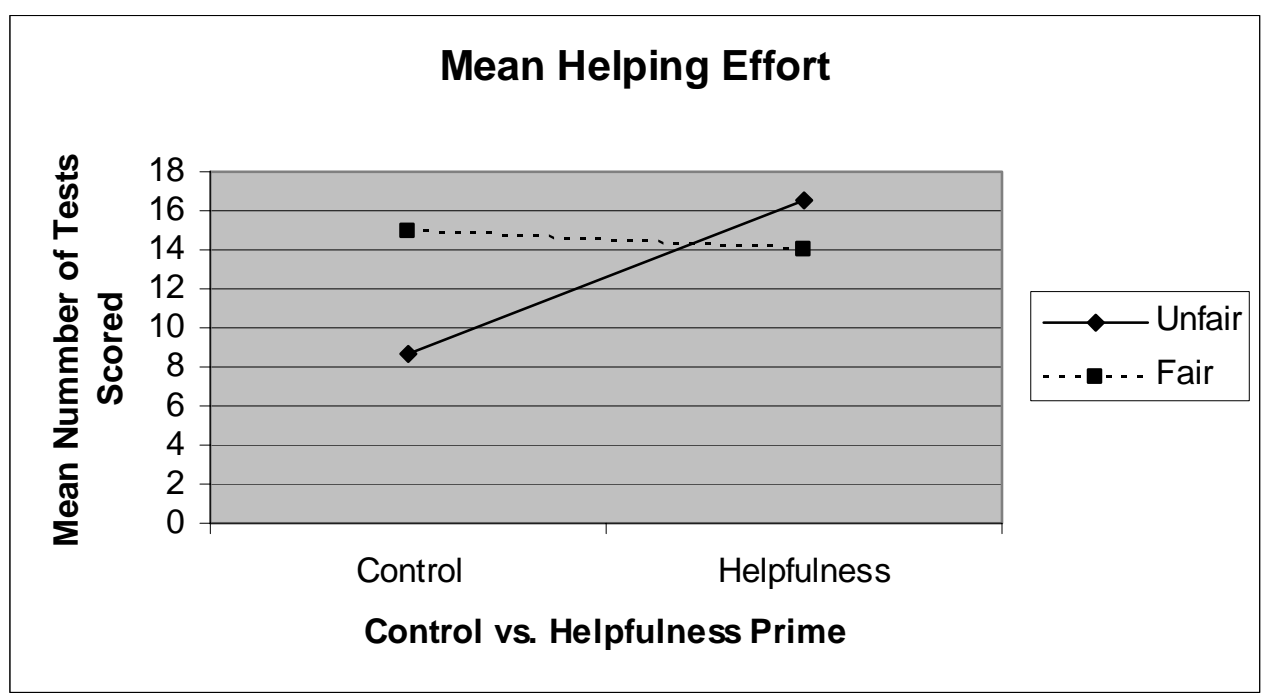


8 TABLES 
Table 1

Summary of Proposed or Investigated Antecedents of Organizational Citizenship Behaviors

\begin{tabular}{|c|c|c|c|c|c|c|c|c|c|c|c|c|c|c|c|c|c|c|c|c|c|}
\hline & 1 & 2 & 3 & 4 & 5 & 6 & 7 & 8 & 9 & 10 & 11 & 12 & 131 & $14 \quad 15$ & 16 & 17 & 18 & 19 & $20 \quad 2$ & 21 & 22 \\
\hline J.S. & & & & $\mathbf{X}$ & & & & & & $\mathbf{X}$ & $\mathbf{X}$ & & & & & & & & & & $\mathbf{X}$ \\
\hline $\begin{array}{l}\text { J.S. as proxy } \\
\text { for Affect }\end{array}$ & $\mathbf{X}$ & $\mathbf{X}$ & & & $\mathbf{X}$ & & $\mathbf{X}$ & $\mathbf{X}$ & $\mathbf{X}$ & & & & & & & & & & & & \\
\hline $\begin{array}{l}\text { J.S. as proxy } \\
\text { for Fairness }\end{array}$ & $\mathbf{X}$ & & & & $\mathbf{X}$ & & $\mathbf{X}$ & $\mathbf{X}$ & $\mathbf{X}$ & & & & & & & & & & & & \\
\hline Trait Affect & & & $\mathbf{X}$ & & & $\mathbf{X}$ & $\mathbf{X}$ & & & $\mathbf{X}$ & & & & & & & & & & & \\
\hline State Affect & & & & & & $\mathbf{X}$ & & & & $\mathbf{X}$ & & & $\mathbf{X}$ & & & & & & & $\mathbf{X}$ & \\
\hline $\begin{array}{l}\text { Perceived } \\
\text { Fairness }\end{array}$ & & & $\mathbf{X}$ & $\mathbf{X}$ & & $\mathbf{X}$ & & & & $\mathbf{X}$ & $\mathbf{X}$ & & $\mathbf{X}$ & & & $\mathbf{X}$ & & & $\mathbf{X} X$ & $\mathbf{X}$ & $\mathbf{X}$ \\
\hline $\begin{array}{c}\text { Equity } \\
\text { Sensitivity }\end{array}$ & & & & & & & & & $\mathbf{X}$ & & & & & & & & & & & & \\
\hline $\begin{array}{l}\text { Leader Style } \\
\& \text { Behaviors }\end{array}$ & & $\mathbf{X}$ & & & & & & $\mathbf{X}$ & & & & & & & & $\mathbf{X}$ & $\mathbf{X}$ & & & & \\
\hline Commitment & & & & & $\mathbf{X}$ & & & & & & $\mathbf{X}$ & & & & & & & & & & $\mathbf{X}$ \\
\hline Personality & & $\mathbf{X}$ & & & & & & & $\mathbf{X}$ & & & $\mathbf{X}$ & & & & & & & & & \\
\hline Task Scope & & $\mathbf{X}$ & & $\mathbf{X}$ & & & & & & & & & & & & & & & & & \\
\hline Norms & & & & & & & & & & & & & & $\mathbf{X}$ & & & & & & & \\
\hline Empathy & & & & & & & & & & & & & & & & & & $\mathbf{X}$ & $\mathbf{X}$ & & \\
\hline $\begin{array}{l}\text { OCB Role } \\
\text { Definition/ } \\
\text { Identity }\end{array}$ & & & & & & & & & & $\mathbf{X}$ & & & & $\mathbf{X}$ & $\mathbf{X}$ & & & & & & \\
\hline $\begin{array}{l}\text { Motives for } \\
\text { Helping }\end{array}$ & & & & & & & & & & $\mathbf{X}$ & & $\mathbf{X}$ & $\mathbf{X}$ & $\mathbf{X}$ & & & & & & & \\
\hline $\begin{array}{l}\text { Prosocial } \\
\text { Personality }\end{array}$ & & & & & & & & & & $\mathbf{X}$ & & & $\mathbf{X}$ & & & & & & & & \\
\hline $\begin{array}{c}\text { Other } \\
\text { Individual } \\
\text { Differences }\end{array}$ & & & & & & & & & & & & $\mathbf{X}$ & & & & $\mathbf{X}$ & & $\mathbf{X}$ & $\mathbf{X}$ & & \\
\hline $\begin{array}{l}\text { Note. J.S. = Jo } \\
3=\text { Organ \& I } \\
\text { George (1991) } \\
=\text { Penner, Mid } \\
(2001) ; 14=\mathrm{El} \\
\text { Shaffer (2004) } \\
\text { Kamdar, McA } \\
\text { Analysis, } 2007\end{array}$ & $\begin{array}{l}7=1 \\
i, \& \\
\text { ihart } \\
18= \\
\text { ister }\end{array}$ & $\begin{array}{l}\text { Moor } \\
\text { Kege } \\
\& \mathrm{~N} \\
\text { Dine }\end{array}$ & $\begin{array}{l}\text { nan } \\
\text { mey } \\
\text { uma } \\
\text { n, L }\end{array}$ & $\begin{array}{l}\text { or Re } \\
) ; 4= \\
1993 \\
\text { er (19 } \\
\text { hn (2 } \\
\text { ewick } \\
\text { (200 }\end{array}$ & $\begin{array}{l}\text { Farh, } \\
\text {; } 8 \text {, } \\
\text { 07); } \\
\text { i, \& }\end{array}$ & $\begin{array}{l}\text { h Stu } \\
\text {, Pod } \\
=\text { Schr } \\
11=\mathrm{S} \\
15=\mathrm{F} \\
\text { Toml } \\
=\mathrm{Me}\end{array}$ & $\begin{array}{l}\text { dies: } \\
\text { lsako } \\
\text { nake, } \\
\text { Schar } \\
\text { Finke } \\
\text { linsor } \\
\text { esser }\end{array}$ & $\begin{array}{l}1= \\
\text { ff, \& } \\
\text { Coc } \\
\text { ope }( \\
\text { lsteir } \\
\text { (20 } \\
\& \text { W }\end{array}$ & $\begin{array}{l}\text { Bate } \\
\text { Org } \\
\text { hran, } \\
1998 \\
\text { \& \& P } \\
\text { 06); }\end{array}$ & $\begin{array}{l}\operatorname{man} \\
\text { an }(1 \\
\& \mathrm{D} \\
; 12= \\
\text { enne } \\
19=\mathrm{J} \\
(200\end{array}$ & 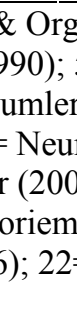 & $\begin{array}{l}\operatorname{san}(1 \\
5=\mathrm{V} \\
\mathrm{r}(199 \\
\operatorname{man} \\
) 4) ; 1 \\
\operatorname{an}, \mathrm{K} \\
=\text { Ho }\end{array}$ & $\begin{array}{l}\text { 1983); } \\
\text { Williai } \\
\text { 95); } 9 \\
\text { \& Kic } \\
\text { 6= Vc } \\
\text { Kamda } \\
\text { ffman }\end{array}$ & $\begin{array}{l}; 2=\mathrm{Sn} \\
\mathrm{ims} \& \mathrm{~A} \\
=\text { Konc } \\
\text { ckul (19 } \\
\text { ey \& Ca } \\
\text { ar, Dani } \\
\text { n, Blair, }\end{array}$ & $\begin{array}{l}\text { ith, } \\
\text { iders } \\
\text { vsky } \\
\text { 98); } 1 \\
\text { mpbe } \\
\text { ls \& } \\
\text { Meri }\end{array}$ & $\begin{array}{l}\text { rgan } \\
\text { on }(1 \\
\& \text { Or } \\
3=\mathrm{R} \\
11(20 \\
\text { Duel } \\
\mathrm{c}, \&\end{array}$ & $\begin{array}{l}\text { \& N } \\
991) ; \\
\text { gan ( } \\
\text { ioux } \\
04) ; \\
1(200 \\
\text { Woel }\end{array}$ & $\begin{array}{l}\text { Jear } \\
6= \\
1996 \\
\& \mathrm{Pe} \\
17=\mathrm{T} \\
06) ; 2 \\
\mathrm{hr}(\mathrm{M}\end{array}$ & $\begin{array}{l}\text { 1983); } \\
\text { ); } 10 \\
\text { aner } \\
\text { Wat \& } \\
2= \\
\text { leta- }\end{array}$ & & \\
\hline
\end{tabular}


Table 2

Percentage of Helpers in each Condition of the 2(Helpfulness) $x$ 2(Fairness) design $(N=194)$

\section{Condition}

Helping Prime Control Prime

\begin{tabular}{lcccc}
\hline & Fair & Unfair & Fair & Unfair \\
Condition $n$ & 49 & 50 & 47 & 48 \\
Helpers & 40 & 31 & 29 & 13 \\
Percent Helpers & $81.6 \%$ & $62.0 \%$ & $61.7 \%$ & $27.1 \%$ \\
\hline
\end{tabular}


Table 3

Logistic Regression for Prediction of Decision to Help from Helpfulness and Fairness $(N=194)$

\begin{tabular}{|c|c|c|c|c|c|c|c|}
\hline & $B$ & Wald & $\begin{array}{l}\text { Chi-square } \\
\text { Step }\end{array}$ & $\begin{array}{c}\text { Chi-square } \\
\text { Model }\end{array}$ & $\begin{array}{c}-2 \log \\
\text { likelihood }\end{array}$ & $\begin{array}{c}\text { Cox \& } \\
\text { Snell } R^{2}\end{array}$ & $\begin{array}{c}\text { Nagelkerke } \\
R^{2}\end{array}$ \\
\hline \multicolumn{8}{|l|}{ Step 1} \\
\hline Prime Vector & & & & $15.29 * * *$ & 248.35 & .076 & .10 \\
\hline \multicolumn{8}{|l|}{ Step 2} \\
\hline \multirow[t]{2}{*}{ Fair Vector } & $.62 * * *$ & 14.64 & $16.06 * * *$ & & & & \\
\hline & & & & $31.35 * * *$ & 232.29 & .15 & .20 \\
\hline \multirow{3}{*}{$\begin{array}{l}\text { Step } 3 \\
\text { Fair Vector x } \\
\text { Prime Vector }\end{array}$} & & & & & & & \\
\hline & -.12 & .52 & .52 & & & & \\
\hline & & & & $31.87 * * *$ & 231.77 & .15 & .20 \\
\hline
\end{tabular}

Note. ${ }^{*} \mathrm{p}<.05 .{ }^{* *} \mathrm{p}<.01 .{ }^{* * *} \mathrm{p}<.001$. 
Table 4

Descriptive Statistics for Helpers with Helping Effort $(n=113)$

\section{Condition}

\begin{tabular}{cccc}
\hline \multicolumn{2}{c}{ Helpfulness Prime } & \multicolumn{2}{c}{ Control Prime } \\
Fair $(n=40)$ & Unfair $(n=31)$ & Fair $(n=29)$ & Unfair $(n=13)$ \\
13.98 & 16.58 & 14.93 & 8.62 \\
6.25 & 5.95 & 6.22 & 5.24 \\
0.99 & 1.07 & 1.15 & 1.45 \\
$1-25$ & $5-30$ & $1-26$ & $1-16$
\end{tabular}


Table 5

Summary of MRA for Helpers for predicting Helping Effort from the 2 (Helpfulness) $x 2$

(Fairness) design (n=113)

\begin{tabular}{lccccc}
\hline Variable & $B$ & $t$ & $\Delta R^{2}$ & $\Delta F$ & $R^{2}$ \\
\hline Step 1 & $1.75^{* *}$ & 2.82 & & & \\
Helpfulness & 0.93 & 1.49 & & & \\
Fairness & & & & & \\
& & & 0.027 & 1.54 & \\
Step 2 & -2.23 & -3.59 & & & \\
Helpfulness X Fairness & & & & & \\
& & & $0.10 * *$ & & \\
& & & & & \\
\end{tabular}

Note. ${ }^{*} \mathrm{p}<.05 .{ }^{* * \mathrm{p}}<.01$ 